NASA TECHNICAL NOTE

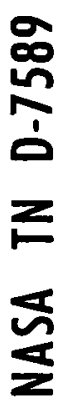

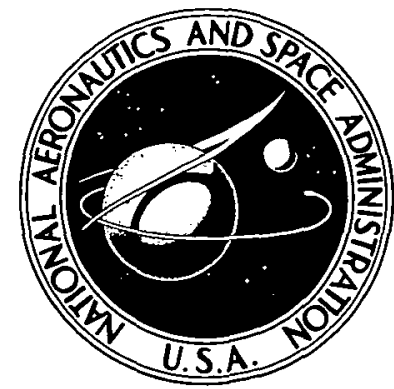

NASA TN $0-7589$

COMPUTER PROGRAM FOR

THERMODYNAMIC ANALYSIS OF OPEN-CYCLE

MULTISHAFT POWER SYSTEM WITH

MULTIPLE REHEAT AND INTERCOOL

by Arthur J. Glassman

Lewis Research Center

Cleveland, Obio 44135

national aEronautics and SpaCe administration - Washington, D. C. • MarCh 1974 


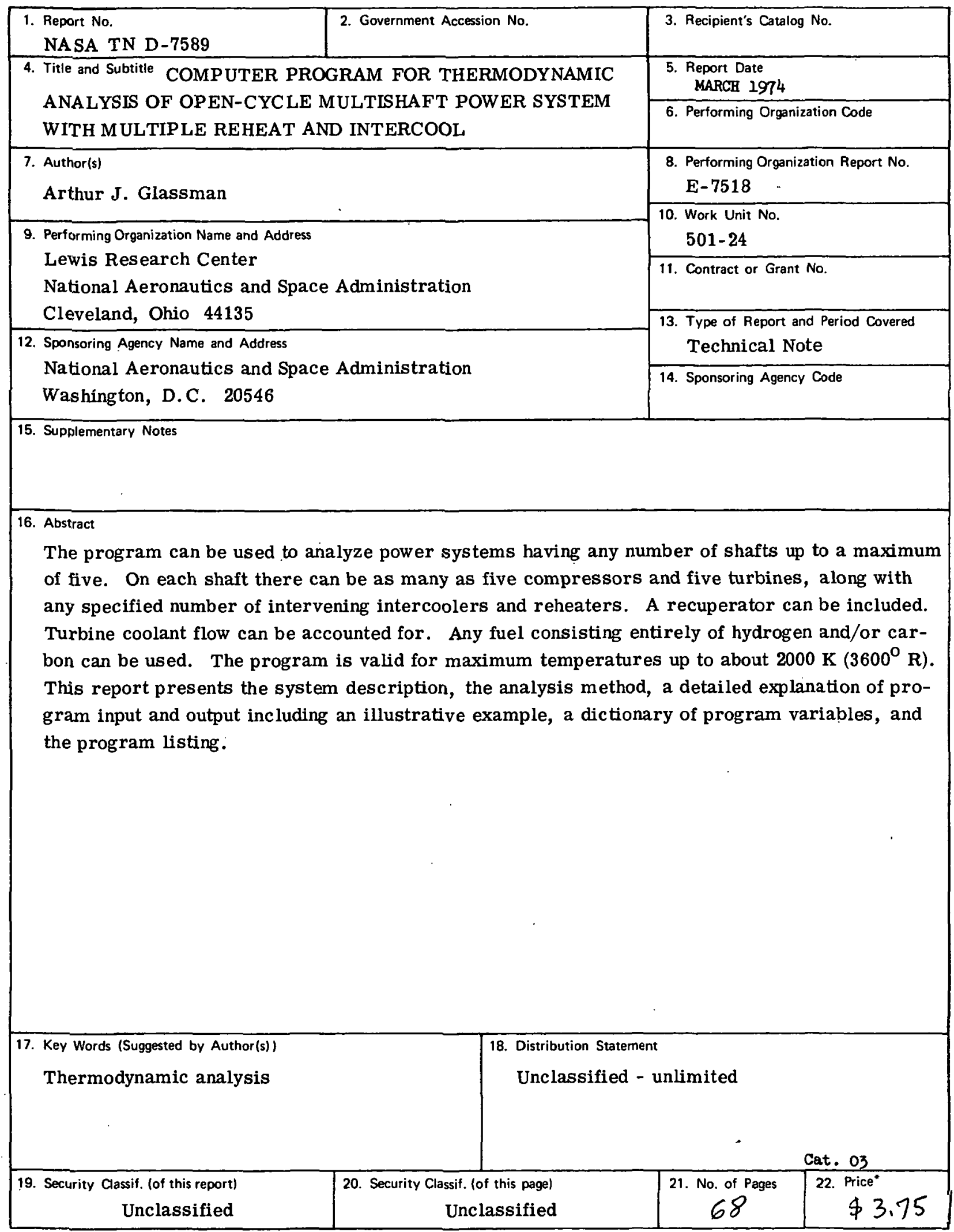

${ }^{*}$ For sale by the National Technical Information Service, Springfield, Virginia 22151 


\title{
COMPUTER PROGRAM FOR THERMODYNAMIC ANALYSIS OF OPEN-CYCLE MULTISHAFT POWER SYSTEM WITH MULTIPLE REHEAT AND INTERCOOL
}

\author{
by Arthur J. Glassman
}

Lewis Research Center

\author{
SUMMARY
}

This report presents a computer program for the thermodynamic analysis of an open-cycle multishaft power system with multiple intercooling and reheating capability. The program can compute specific power output, specific fuel consumption, and cycle efficiency for power systems having any number of shafts up to a maximum of five. On each shaft there can be any number of compressors and turbines up to a maximum of five each, along with any specified number of intervening intercoolers and reheaters. A recuperator can be included in the system. Turbine coolant flow can be accounted for. The combustion-gas thermodynamic properties are valid for any fuel consisting of hydrogen and/or carbon only. The program should be used with maximum temperatures no higher than about $2000 \mathrm{~K}\left(3600^{\circ} \mathrm{R}\right)$ because molecular dissociation is not included in the stoichiometry.

This report presents a description of the general open-cycle system that can be analyzed, the analysis method, and a complete description of the computer program. The description of the computer program includes a detailed explanation of input and output including an illustrative example, a discussion of the main program and each of the subprograms, the dictionary of program variables, and the program listing.

\section{INTRODUCTION}

Open-cycle systems for ground power-production applications, both stationary and propulsive, are currently being studied at the Lewis Research Center. One of the first phases in the analysis of any power cycle is the determination of the thermodynamic performance as a function of the cycle variables. Such cycle analyses are performed most readily by computer. Therefore, a computer program was written to perform the thermodynamic analysis of open-cycle power systems. 
The computer program can be used to analyze power systems having any number of shafts up to a maximum of five. On each shaft there can be any number of compressors and turbines up to a maximum of five each, along with intervening intercoolers and reheat combustors. A recuperator can be included in the system, and turbine coolant flow can be accounted for. Any fuel consisting entirely of hydrogen and/or carbon can be used. The program should be used with maximum temperatures no higher than about $2000 \mathrm{~K}\left(3600^{\circ} \mathrm{R}\right)$ because molecular dissociation is not included in the stoichiometry.

This report presents a description of the general open-cycle system that can be analyzed, the analysis method, and a complete description of the computer program. The computer program description includes a detailed explanation of input and output including a sample case, a discussion of the main program and each of the subprograms, a program listing, and a dictionary of program variables.

\section{SYSTEM ANALYSIS AND DESCRIPTION}

An example two-shaft power system is used to show the type of analysis that can be performed by the computer program being described in this report. The general opencycle power system that can be analyzed is then described.

\section{Example-System Analysis}

An example of a power system that can be analyzed using the computer program described herein is the two-shaft open-cycle power system with intercooling and reheating that is shown schematically in figure 1 and thermodynamically on a temperature-entropy diagram in figure 2. Air enters the low-pressure compressor and is partially compressed. The air is then cooled within the intercooler. Since heat is generated during compression and compressor work is proportional to temperature, the use of intercooling serves to reduce the total compression work required for a given pressure ratio. The cooled air is then further compressed in the high-pressure compressor and heated in the combustor by the burning of fuel. Partial expansion occurs in the high-pressure turbine, which drives the high-pressure compressor, and heating again occurs, this time in the reheater. Since turbine work is proportional to temperature, the use of reheating increases the total work obtained for a given expansion. Final expansion to atmospheric pressure then occurs in the low-pressure turbine, which drives both the lowpressure compressor and the generator.

The computer program described in this report can be used to analyze such a power system to determine cycle efficiency as a function of turbine-inlet temperature and compressor pressure ratio. The improvements in cycle efficiency resulting from the use of 
intercooling and reheating can also be determined. Cycle efficiency computed by the program is plotted against turbine-inlet temperature in figure 3 for a system with one intercooling and one reheating (fig. 1), a system with one intercooling only, and a simple system (no intercooling and no reheating). For these three systems an increase in turbine-inlet temperature from 1090 to $1370 \mathrm{~K}\left(1500^{\circ}\right.$ to $\left.2000^{\circ} \mathrm{F}\right)$ increases cycle efficiency by about 20 to 25 percent; a further increase from 1370 to $1650 \mathrm{~K}\left(2000^{\circ}\right.$ to $2500^{\circ} \mathrm{F}$ ) increases cycle efficiency by another 10 to 15 percent. Operation at higher turbine-inlet temperatures, therefore, results in significant improvements in cycle efficiency.

The improvements in cycle efficiency resulting from intercooling and reheating are also indicated in figure 3. At a temperature of $1370 \mathrm{~K}\left(2000^{\circ} \mathrm{F}\right)$ as an example, the use of one intercooling alone increases the efficiency from 39 to 43 percent and the addition of one reheating along with the intercooling increases efficiency to 45 percent. For a plant of fixed power output, this corresponds to about a 10-percent reduction in fuel consumption with intercooling and about 5-percent additional reduction in fuel consumption with the reheating added. At other temperatures, the benefits are about the same magnitude with efficiency reaching about 50 percent at $1650 \mathrm{~K}\left(2500^{\circ} \mathrm{F}\right)$. The reductions in fuel cost associated with such improvements in efficiency must be considered against the additional capital cost of the plant. Additional intercoolings and reheatings can be used to yield further improvements in cycle efficiency. The incremental improvements, however, become smaller and smaller as additional intercool and reheat steps are added. The optimum number of intercoolers and reheaters to be used will depend on a detailed economic analysis for a given plant.

In order to realize the benefits associated with the use of intercooling and reheating, the system must operate at greater pressure ratios than the simple cycle. This is indicated in figure 4 , where cycle efficiencies for the simple system and for a system with one intercooling and one reheating are plotted against pressure ratio at a turbine-inlet temperature of $1370 \mathrm{~K}\left(2000^{\circ} \mathrm{F}\right)$, as an example. For the simple cycle the optimum pressure ratio is 30 , and efficiency decreases markedly if the pressure ratio is less than 20 or greater than 40 . For the cycle with intercooling and reheating, the optimum pressure ratio is about 120 . However, the curve is very flat in the region of maximum efficiency, and it is possible to operate at a pressure ratio of about 75 without a significant decrease in efficiency. This pressure ratio of 75 is still considerably higher than that for the simple cycle. Thus, with intercooling and reheating, not only will additional heat exchangers be required, but also additional stages will be required for the turbomachinery. 
The example system just discussed is only one of many possible variations for opencycle power systems. The computer program presented in this report can be used to analyze open-cycle power systems having different numbers and types of components. Figure 5(a) shows schematically a system having the maximum number of components that can be included in the analysis; figure $5(\mathrm{~b})$ shows a system having the minimum number of components that must be included. Any system intermediate between these two can be analyzed. The size of the maximum system was selected on the basis of it being large enough to include all cases of possible interest.

In figure 5(a) the system capability includes an inlet, a series of compressors and intercoolers, a recuperator, a primary burner, a series of turbines and reheaters, and a diffuser. There can be as many as five shafts. On each shaft there can be as many as five compressors with any specified number of intervening intercoolers and five turbines with any specified number of intervening reheaters. Output power can be obtained from each shaft. Part of the compressor exit flow can be used as turbine coolant or lost through recuperator leakage. The turbine coolant, which can be directed to any or all of the turbines, rejoins the primary flow at the exit of the turbine being cooled.

Any liquid or gaseous fuel consisting entirely of hydrogen and/or carbon can be used. A fuel boost pump or compressor, with intercooling if desired, can be provided with the required drive power taken from the system output.

The subscripts shown for the compressors, intercoolers, burners, and turbines correspond to the double subscript notation used in the program. The first subscript refers to the component number, and the second subscript refers to the shaft number. An understanding of the proper order of subscripts is necessary to correctly prepare program input. Specific directions for properly specifying input-variable subscripts are given in the section Description of Input and Output.

\section{METHOD OF ANALYSIS}

The equations used for the open-cycle power system thermodynamic analysis are presented in this section. Equations are presented for the thermodynamic properties of the gas, analysis of the fluid state changes in each component, and computation of the system performance in terms of specific power output, specific fuel consumption, and cycle efficiency. The calculation logic for combining the components into the desired system is discussed as needed. All symbols used in the analysis are defined in appen$\operatorname{dix} \mathbf{A}$. 
To perform a cycle thermodynamic analysis, it is necessary to relate enthalpy change and constant-pressure entropy change to the gas temperature change and composition. This is done herein as follows: The heat capacity $c_{p}$ of each component of the general combustion gas is expressed as a polynomial function of temperature. Then, from the stoichiometry associated with the reaction of 1 mass unit of air plus associated inlet humidity with $f$ mass units of fuel of composition $\mathrm{CH}_{x}$, a single equation for the combustion-gas heat capacity is obtained. Finally, the enthalpy and constantpressure entropy changes are obtained as

$$
\Delta h=\int_{T_{1}}^{T_{2}} c_{p} d T
$$

and

$$
\Delta \varphi=\int_{\mathrm{T}_{1}}^{\mathrm{T}_{2}} \frac{\mathrm{c}_{\mathrm{p}}}{\mathrm{T}} \mathrm{dT}
$$

The equations for $\Delta \mathrm{h}$ and $\Delta \varphi$ as functions of initial $\mathrm{T}_{1}$ and final $\mathrm{T}_{2}$ temperatures, fuel-air ratio $\mathrm{f}$, fuel composition (function of $\mathrm{x}$ ), and absolute humidity of the inlet air are derived in appendix $B$. These equations are valid over a temperature range of 200 to $2000 \mathrm{~K}\left(360^{\circ}\right.$ to $\left.3600^{\circ} \mathrm{R}\right)$. A maximum temperature of $2000 \mathrm{~K}\left(3600^{\circ} \mathrm{R}\right)$ was chosen because the combustion stoichiometry does not include molecular dissociation, which starts to appear at about this temperature. The basic assumption inherent in these thermodynamic equations, as well as in most of the analysis, is that the gas obeys the ideal gas law.

For brevity in the analysis to follow, equation (B7) for $\Delta \mathrm{h}$ and equation (B12) for $\Delta \varphi$ will be denoted as

$$
\Delta \mathrm{h}=\mathrm{H}\left(\mathrm{T}_{1}, \mathrm{~T}_{2}, \mathrm{f}\right)
$$

and

$$
\Delta \varphi=\Phi\left(\mathrm{T}_{1}, \mathrm{~T}_{2}, \mathrm{f}\right)
$$

Since the fuel composition and inlet-air absolute humidity have singular values for any given system analysis, they were not included as arguments of these functions. 


\section{Components}

The equations used to analyze the flow through the inlet, compressors, intercoolers, burners, turbines, diffuser, recuperator, and fuel system are presented in this section.

Inlet. - Since this is a ground-based power system, inlet total and static conditions were assumed equal. The inlet component would probably be some type of air filter. Therefore, for the flow leaving the inlet

$$
\begin{gathered}
\mathrm{T}_{1}^{\prime}=\mathrm{T}_{0} \\
\mathrm{p}_{1}^{\prime}=\mathrm{p}_{0} \mathrm{r}_{\mathrm{I}} \\
\mathrm{w}_{1}=1+\mathrm{m}
\end{gathered}
$$

The ambient static temperature $T_{0}$, ambient static pressure $p_{0}$, inlet pressure recovery $r_{I}$, and inlet absolute humidity $m$ are program inputs.

Compressor. - The compressors and intercoolers are analyzed in flow sequence. The inlet conditions to the first compressor are those from the inlet component as specified by equations (5) to (7). For any subsequent compressor, the inlet conditions are the exit conditions from the component, either a compressor or an intercooler, immediately upstream. The mass flow rate remains constant at $w_{1}$ throughout the compressors and intercoolers.

For any compressor

$$
\mathrm{p}_{\mathrm{C}, \mathrm{ex}}^{\prime}=\mathrm{p}_{\mathrm{C}, \text { in }}^{\prime} \mathrm{r}_{\mathrm{C}}
$$

where the pressure ratio $r_{C}$ for each compressor is specified by the input variables. Either an overall efficiency $\eta_{C, o}$ or a polytropic efficiency $\eta_{C, p}$ can be specified for the compressor. With overall efficiency, an ideal exit temperature $T_{C}^{\prime}$, ex, id is found by iteration from

$$
\Phi\left(\mathrm{T}_{\mathrm{C}, \text { in }}^{\prime}, \mathrm{T}_{\mathrm{C}, \mathrm{ex}, \mathrm{id}}^{\prime}, 0\right)=\frac{\mathrm{R}}{\mathrm{J}} \ln \mathrm{r}_{\mathrm{C}}
$$

Compressor specific work is then found from the efficiency definition

$$
\Delta h_{C}^{\prime}=\frac{H\left(T_{C, \text { in }}^{\prime}, T_{C, e x, i d}^{\prime}, 0\right)}{\eta_{C, o}}
$$

and compressor exit temperature from 


$$
\mathrm{H}\left(\mathrm{T}_{\mathrm{C}, \text { in }}^{\prime}, \mathrm{T}_{\mathrm{C}, \text { ex }}^{\prime}, 0\right)=\Delta \mathrm{h}_{\mathrm{C}}^{\prime}
$$

With polytropic efficiency, the compressor exit temperature is found from

$$
\Phi\left(\mathrm{T}_{\mathrm{C}, \text { in }}^{\prime}, \mathrm{T}_{\mathrm{C}, \text { ex }}^{;}, 0\right)=\frac{1}{\eta_{\mathrm{C}, \mathrm{p}}} \frac{\mathrm{R}}{\mathrm{J}} \ln \mathrm{r}_{\mathrm{C}}
$$

and compressor specific work from

$$
\Delta \mathrm{h}_{\mathrm{C}}^{\prime}=\mathrm{H}\left(\mathrm{T}_{\mathrm{C}, \mathrm{in}}^{\prime}, \mathrm{T}_{\mathrm{C}, \mathrm{ex}}^{\prime}, 0\right)
$$

For each shaft, the compressor specific works are summed in order to obtain the turbine power required to drive the compressors on that shaft:

$$
\mathrm{P}_{\mathrm{C}, \mathrm{j}}=\mathrm{w}_{1} \sum \Delta \mathrm{h}_{\mathrm{C}, \mathrm{j}}^{\mathrm{\prime}}
$$

Intercooler. - The inlet conditions to each intercooler are the exit conditions from the compressor immediately upstream. The exit temperature from each intercooler is specified as program input, and the exit pressure is determined from the input pressure recovery $\mathbf{r}_{\text {INT }}$

$$
\mathrm{p}_{\mathrm{INT}, \mathrm{ex}}^{\prime}=\mathrm{p}_{\mathrm{INT}, \text { in }^{\mathrm{r}} \mathrm{INT}}^{\mathrm{IN}}
$$

The heat rejected in each intercooler can be found as

$$
\Delta \mathrm{h}_{\mathrm{INT}}^{\prime}=\mathrm{H}\left(\mathrm{T}_{\mathrm{INT}, \mathrm{ex}}^{\prime}, \mathrm{T}_{\mathrm{INT}, \text { in }}^{\prime}, 0\right)
$$

Recuperator cold side. - Entering the recuperator cold side is the last (highest pressure) compressor exit flow having temperature $T_{2}^{\prime}$ and pressure $p_{2}^{\prime}$. Some of this compressor-exit flow is bled off for turbine coolant or to account for a leakage loss such as in a rotary recuperator. The mass flow rate entering the recuperator is then

$$
\mathrm{w}_{2}=\mathrm{w}_{1}-\mathrm{w}_{l}-\sum \mathrm{w}_{\mathrm{T}, \mathrm{c}}
$$

The leakage flow $w_{l}$ and the coolant flow $w_{T, c}$ required for each turbine are specified by the program input. The recuperator cold-side exit pressure is determined from the 
input value of pressure recovery $r_{R, \text { cold }}$ :

$$
\mathrm{p}_{3}^{\prime}=\mathrm{p}_{2}^{\prime} \mathrm{r}_{\mathrm{R}, \text { cold }}
$$

At this point in the analysis it is necessary to enter an iteration loop. The recuperator cold-side exit temperature $T_{3}^{\prime}$ cannot be determined until the hot-side inlet temperature $\mathrm{T}_{6}^{\prime}$ is known. The value of $\mathrm{T}_{6}^{\prime}$ depends on the turbine flow rate, which in turn depends on the fuel added in the primary burner $\left(B_{11}\right)$, which in turn depends on the temperature $T_{3}^{\prime}$. Since the fuel flow is small as compared with the air flow, convergence is rapid. As a first estimate,

$$
\mathrm{T}_{3, \text { est }}^{\prime}=\mathrm{T}_{2}^{\prime}+\frac{\eta_{\mathrm{R}}}{2}\left(\mathrm{~T}_{4}^{\prime}-\mathrm{T}_{2}^{\prime}\right)
$$

where the primary burner exit temperature $T_{4}^{\prime}$ is a program input. The remainder of the recuperator analysis is presented later in proper sequence.

Burner. - The burners and turbines are analyzed in flow sequence. Gas entering the primary burner comes from the cold side of the recuperator, and gas entering any reheat burner comes from the turbine immediately upstream. In the general case, gas enters the burner with temperature $T_{B \text {, in }}^{\prime}$, pressure $p_{B \text {, in }}^{\prime}$, and mass flow rate $w_{B}$, in having a composition corresponding to a fuel-air ratio of $\mathrm{f}_{\mathrm{B}}$, in . For the primary burner, $T_{B \text {, in }}^{\prime}=T_{3}^{\prime}, p_{B, \text { in }}^{\prime}=p_{3}^{\prime}, w_{B, \text { in }}=w_{2}$, and $f_{B, \text { in }}=0$. Gas leaves the burner with temperature $T_{B}^{\prime}$, ex , which is a program input, and pressure $p_{B}^{\prime}$, ex' which is determined from the input value of pressure recovery $r_{B}$

$$
\mathrm{p}_{\mathrm{B}, \mathrm{ex}}^{\prime}=\mathrm{p}_{\mathrm{B}, \text { in }^{\mathrm{r}} \mathrm{B}}
$$

and with flow

$$
{ }_{B}, \text { ex }=w_{B, \text { in }}+w_{f, B}
$$

where $w_{f, B}$ is the fuel flow added to this particular burner. The associated fuel-air ratio is

$$
f_{B, \text { ex }}=\frac{w_{f, B, \text { ex }}}{w_{\text {air }, B}}=\frac{w_{f, B, \text { in }}+w_{f, B}}{w_{\text {air }, B}}=f_{B, \text { in }}+f_{B}
$$

where $w_{f, B}$, in is the amount of fuel added in previous burners and $w_{\text {air, }}$, is the burner air flow (fraction of original inlet air that exists in the flow in this burner).

The fuel flow $w_{f, B}$ is found from a burner energy balance, which can be expressed with respect to a reference temperature $T_{r}$ as 


$$
\begin{aligned}
w_{f, B} H_{f}\left(T_{r}, T_{f}^{\prime}\right)+\eta_{B} w_{f, B} \Delta h_{c b}+w_{B, \text { in }} H\left(T_{r}, T_{B, \text { in }}^{\prime}, f_{B, \text { in }}\right) & \\
= & w_{B, e x}{ }^{H}\left(T_{r}, T_{B, e x}^{\prime}, f_{B, e x}\right)
\end{aligned}
$$

The heat of combustion $\Delta \mathrm{h}_{\mathrm{cb}}$ must be that at the reference temperature $\mathrm{T}_{\mathrm{r}}$ and is a program input along with the burner efficiency $\eta_{B}$. The fuel enthalpy term $\mathrm{H}_{f}$ is a polynomial expression defined by equations (C2) and (C4) of appendix C. Fuel temperature $T_{f}^{\prime}$ is either the fuel inlet temperature $T_{f, \text { in }}^{\prime}$ or the fuel-compressor exit temperature $T_{f, C}^{\prime}$, ex as obtained from equation (C8). The right-hand side (RHS) of equation (23) can be expressed in the form of equation (B9)

$$
R H S=w_{B, e x}\left(\frac{1}{1+f_{B, e x}+m}\right)\left[(1+m) H\left(T_{r}, T_{B, e x}^{\prime}, 0\right)+f_{B, e x} I\left(T_{r}, T_{B, e x}^{\prime}\right)\right]
$$

Substituting for $f_{B \text {, ex }}$ from equation (22), equating the constant air flow in terms of inlet and exit conditions such that

$$
w_{\text {air, } B}=\frac{w_{B, \text { ex }}}{1+f_{B, \text { ex }}+m}=\frac{w_{B, \text { in }}}{1+f_{B, \text { in }}+m}
$$

and expressing $\mathrm{w}_{\mathrm{f}, \mathrm{B}}$ as

$$
w_{f, B}=f_{B} w_{\text {air, } B}
$$

yield for equation (24)

$$
\begin{aligned}
& R H S=w_{B, \text { in }}\left(\frac{1}{1+f_{B, \text { in }}+m}\right)\left[(1+m) H\left(T_{r}, T_{B, \text { ex }}^{\prime}, 0\right)+f_{B, \text { in }} I\left(T_{r}, T_{B, \text { ex }}^{\prime}\right)\right] \\
& +w_{f, B} I\left(T_{r}, T_{B, e x}^{\prime}\right)
\end{aligned}
$$

In accordance with equation (B9), equation (26) can be expressed as

$$
\text { RHS }=w_{B, \text { in }} H\left(T_{r}, T_{B, ~ e x}^{\prime}, f_{B, \text { in }}\right)+w_{f, B} I\left(T_{r}, T_{B, e x}^{\prime}\right)
$$

Now, substituting equation (27) back into equation (23), combining terms, and rearranging yield 


$$
w_{f, B}=\frac{{ }_{B, \text { in }}^{H}\left(T_{B, \text { in }}^{\prime}, T_{B, \text { ex }}^{\prime}, f_{B, \text { in }}\right)}{H_{f}\left(T_{r}, T_{f}^{\prime}\right)+\eta_{B} \Delta h_{c b}-I\left(T_{r}, T_{B, e x}^{\prime}\right)}
$$

Turbine. - Flow into any turbine comes either from a burner or from another turbine. The exact nature of the turbine calculation depends on which shaft the turbine is on. For a multishaft system the drive power for all shafts other than the low-pressure shaft $\left(j \neq n_{s h}\right)$ is

$$
P_{T, j}=P_{C, j} K_{P}
$$

where $P_{C, j}$ is obtained from equation (14) and $K_{P}$ is a factor (program input) to allow for output power from the shaft. With the shaft power $P_{T, j}$ known, the power $P_{T}$ for each turbine is obtained from program input. "Turbine specific work is then determined as

$$
\Delta \mathrm{h}_{\mathrm{T}}^{\prime}=\frac{\mathrm{P}_{\mathrm{T}}}{\mathrm{w}_{\mathrm{T}, \text { in }}}
$$

and turbine exit temperature from

$$
\mathrm{H}\left(\mathrm{T}_{\mathrm{T}, \text { ex }}^{\prime}, \mathrm{T}_{\mathrm{T}, \text { in }}^{\prime}, \mathrm{f}_{\mathrm{T}, \text { in }}\right)=\Delta \mathrm{h}_{\mathrm{T}}^{\prime}
$$

Either an overall efficiency $\eta_{\mathrm{T}, \mathrm{o}}$ or a polytropic efficiency $\eta_{\mathrm{T}, \mathrm{p}}$ can be specified for each turbine. With overall efficiency, the turbine ideal work is obtained as

$$
\Delta \mathrm{h}_{\mathrm{T}, \mathrm{id}}^{\prime}=\frac{\Delta \mathrm{h}_{\mathrm{T}}^{\prime}}{\eta_{\mathrm{T}, \mathrm{o}}}
$$

and turbine ideal exit temperature from

$$
\mathrm{H}\left(\mathrm{T}_{\mathrm{T}, \text { ex, id }}^{\prime}, \mathrm{T}_{\mathrm{T}, \text { in }}^{\prime}, \mathrm{f}_{\mathrm{T}, \text { in }}\right)=\Delta \mathrm{h}_{\mathrm{T}, \text { id }}^{\prime}
$$

Turbine exit pressure is then

$$
\mathrm{p}_{\mathrm{T}, \text { ex }}^{\prime}=\mathrm{p}_{\mathrm{T}, \text { in }}^{\prime} \exp \left[\frac{J}{R} \Phi\left(\mathrm{T}_{\mathrm{T}, \text { in }}^{\prime}, \mathrm{T}_{\mathrm{T}, \text { ex, id }}^{\prime}, \mathrm{f}_{\mathrm{T}, \text { in }}\right)\right]
$$

With polytropic efficiency, turbine exit pressure is

$$
\mathrm{p}_{\mathrm{T}, \text { ex }}^{\prime}=\mathrm{p}_{\mathrm{T}, \text { in }}^{\prime} \exp \left[\frac{\mathrm{J}}{\mathrm{R} \eta_{\mathrm{T}, \mathrm{p}}} \Phi\left(\mathrm{T}_{\mathrm{T}, \text { in }}^{\prime}, \mathrm{T}_{\mathrm{T}, \text { ex }}^{\prime}, \mathrm{f}_{\mathrm{T}, \text { in }}\right)\right]
$$


For a single-shaft system and for the low-pressure shaft of a multishaft system, the pressure ratio across the shaft is determined from the last turbine exit pressure

$$
\mathrm{p}_{5}^{\prime}=\mathrm{p}_{0}\left(\frac{\mathrm{p}_{7}^{\prime}}{\mathrm{p}_{0}}\right) \frac{1}{\mathrm{r}_{\mathrm{R}, \operatorname{hot}^{\mathrm{r}} \mathrm{D}}}
$$

where the recuperator-exit total-to-static pressure ratio $\mathrm{p}_{7}^{\prime} / \mathrm{p}_{0}$, the recuperator hotside pressure recovery $r_{R \text {, hot }}$, and the diffuser pressure recovery $r_{D}$ are program inputs. The individual turbine inlet and exit pressures $\mathrm{p}_{\mathrm{T}}^{\prime}$, in and $\mathrm{p}_{\mathrm{T}}^{\prime}$, ex are then obtained from the input pressure ratio distribution. With polytropic efficiency specified, turbine exit temperature $T_{\mathrm{T}}^{\prime}$, ex, specific work $\Delta \mathrm{h}_{\mathrm{T}}^{\prime}$, and power $\mathrm{P}_{\mathrm{T}}$ are determined from equations (35), (31), and (30), respectively. With overall efficiency specified, turbine specific work $\Delta \mathrm{h}_{\mathrm{T}}^{\prime}$ is determined from equations (34), (33), and (32) in that order. Turbine exit temperature $\mathrm{T}_{\mathrm{T}, \text { ex }}^{\prime}$ and power $\mathrm{P}_{\mathrm{T}}$ are then determined from equations (31) and (30), respectively.

For the analysis model, it is assumed that the coolant flow for each turbine bypasses that turbine and then mixes with the exit flow from that turbine. The coolant does not contribute to either turbine work or loss. To make any better assumption would require detailed turbine design information. If such were available, the turbine efficiency could be adjusted to account for effects of the coolant flow. It is assumed that the total pressure $\mathrm{p}_{\mathrm{T}, \mathrm{ex}}^{\prime} \mathrm{m}$ after mixing is equal to the turbine exit total pressure $\mathrm{p}_{\mathrm{T}}^{\prime}$, ex$\cdot$ The mixed total flow rate is equal to

$$
{ }^{w_{T}} \text { ex, } \mathrm{m}=\mathrm{w}_{\mathrm{T}, \text { in }}+\mathrm{w}_{\mathrm{T}, \mathrm{c}}
$$

and the air flow is

$$
\mathrm{w}_{\text {air }, \mathrm{T}, \mathrm{ex}, \mathrm{m}}=\mathrm{w}_{\text {air }, \mathrm{T}, \text { in }}+\mathrm{w}_{\mathrm{T}, \mathrm{c}}\left(\frac{1}{1+\mathrm{m}}\right)
$$

The fuel-air ratio is then

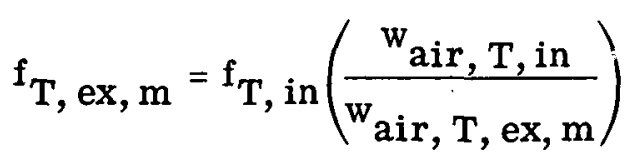

The total temperature $T_{T}^{\prime}$, ex, $m$ after mixing is found from a heat balance for the mixing process:

$$
\left.{ }^{w_{T}, e x, m^{H}}{\left(T_{c}^{\prime}, T_{T}^{\prime}, e x, m\right.}^{\prime} f_{T, e x, m}\right)=w_{T, \text { in }}{ }^{H}\left(T_{c}^{\prime}, T_{T, e x}^{\prime}, f_{T, \text { in }}\right)
$$


The coolant temperature $T_{c}^{\prime}$ is either the last-compressor exit temperature $T_{2}^{\prime}$ or some input value.

Diffuser. - A diffuser is included in the system to allow for a loss when diffusing the high-velocity turbine-exit flow to the low velocity desired in the recuperator. The diffuser-exit total pressure is determined from the input value of pressure recovery $r_{D}$

$$
\mathrm{p}_{6}^{\prime}=\mathrm{p}_{5}^{\mathrm{r}} \mathrm{r}_{\mathrm{D}}
$$

All other variables retain the same values as at the exit of the last turbine.

Recuperator. - The recuperator cold-side flow $\mathrm{w}_{2}$ was defined by equation (17) and the cold-side exit pressure $p_{3}^{\prime}$ by equation (18). The hot-side flow is the diffuserexit flow $\mathrm{w}_{6}$, and the hot-side exit total pressure $\mathrm{p}_{7}^{\prime}$ is determined by the input value of pressure recovery $r_{R \text {, hot }}$

$$
\mathrm{p}_{7}^{\prime}=\mathrm{p}_{6}^{\prime} \mathrm{r}_{\mathrm{R}, \text { hot }}
$$

The cold-side exit total temperature $T_{3}^{\prime}$, which was initially estimated using equation (19), can now be computed using the recuperator effectiveness definition:

$$
\mathrm{H}\left(\mathrm{T}_{2}^{\prime}, \mathrm{T}_{3}^{\prime}, 0\right)=\eta_{\mathrm{R}} \mathrm{H}\left(\mathrm{T}_{2}^{\prime}, \mathrm{T}_{6}^{\prime}, 0\right)
$$

If the computed value of $T_{3}^{\prime}$ does not agree with the initial estimate or previously computed value, the calculation loops back to the primary burner for another iteration. After a satisfactory value of $T_{3}^{\prime}$ is found, the hot-side exit total temperature is obtained from a recuperator heat balance:

$$
\mathrm{w}_{6} \mathrm{H}\left(\mathrm{T}_{7}^{\prime}, \mathrm{T}_{6}^{\prime}, \mathrm{f}_{6}\right)=\mathrm{w}_{2} \mathrm{H}\left(\mathrm{T}_{2}^{\prime}, \mathrm{T}_{3}^{\prime}, 0\right)
$$

If there is a recuperator leakage flow, such as in a rotary recuperator, the recuperator hot-side exit throughflow mixes with the leakage to give an exit flow rate of

$$
\mathrm{w}_{8}=\mathrm{w}_{7}+\mathrm{w}_{l}
$$

The mixed temperature $\mathrm{T}_{8}^{\prime}$ is then obtained from a heat balance for the mixing process:

$$
\mathrm{w}_{8} \mathrm{H}\left(\mathrm{T}_{2}^{\prime}, \mathrm{T}_{8}^{\prime}, \mathrm{f}_{8}\right)=\mathrm{w}_{7} \mathrm{H}\left(\mathrm{T}_{2}^{\prime}, \mathrm{T}_{7}^{\prime}, \mathrm{f}_{7}\right)
$$

Overall Performance

The net shaft output power is 


$$
P_{\text {sh, net }}=\sum_{j=1}^{n_{\text {sh }}}\left(P_{T, j}-P_{C, j}\right)-w_{f, \text { tot }} \Delta h_{f, C}^{\prime}
$$

where the fuel-compression specific work $\Delta \mathrm{h}_{\mathrm{f}, \mathrm{C}}^{\prime}$ is obtained from equation (C9). The net plant output power is

$$
\mathrm{P}_{\text {net }}=\eta_{\mathrm{cv}} \mathrm{P}_{\mathrm{sh}, \mathrm{net}}
$$

where the conversion efficiency $\eta_{\mathrm{cv}}$ reflects a generator, gearbox, or other device.

The specific fuel consumption is

$$
\mathrm{SFC}=\frac{3600 \mathrm{w}_{\mathrm{f}, \text { tot }}}{\mathrm{P}_{\text {net }}}
$$

and the cycle efficiency is

$$
\eta_{c y}=\frac{P_{\text {net }}}{w_{f, \text { tot }} \Delta \mathrm{h}_{\mathrm{cb}}}
$$

\section{DESCRIPTION OF INPUT AND OUTPUT}

This section presents a detailed description of the program input, normal output, and error messages. The input and corresponding printed output for an example power system are included for illustrative purposes.

\section{Input}

A general description of the program input is given and then followed by an illustrative example.

General input. - The data and option indicators are input in data records having the NAMELIST name INPUT. The variables and indicators that compose INP UT along with descriptions, units, and special remarks are presented in the list to follow. Either SI units or U.S. customary units may be used with this program. In this list the symbolism $(X(J), J=1, N)$ means that $X$ is a singly subscripted variable having $N$ values $(\mathrm{X}(1)$ to $\mathrm{X}(\mathrm{N}))$ to be entered into the program unless otherwise indicated. Similarly, the symbolism $((X(I, J), I=1, N) I=1, M)$ means that $X$ is a doubly subscripted variable having $\mathbf{N} \times \mathbf{M}$ Values to be entered into the program unless otherwise indicated. 
The single subscript refers to the shaft number. The first of the double subscripts refers to the component number on each shaft, and the second subscript refers to the shaft number. The order of subscripting is shown in figure 5(a). All subscripted variables are dimensioned to allow for a maximum value of 5 for each subscript.

Values for some of the variables in the input list are internally preset by the program before reading the input. These internally preset values are used by the program if alternate values are not specified by the input. Thus, if a preset value is appropriate, that particular variable does not have to be specified in the input. These internally preset values are shown in the input list that follows:

\begin{tabular}{|c|c|c|}
\hline Variable & Description & Preset value \\
\hline TSO & ambient temperature, $\mathrm{K}\left({ }^{\circ} \mathrm{R}\right)$ & 518.7 \\
\hline PSO & ambient pressure, $\mathrm{N} / \mathrm{cm}^{2}$ (psia) & 14.696 \\
\hline W & ambient air absolute humidity & 0.0 \\
\hline R10 & inlet total pressure recovery & 1.0 \\
\hline NSHAFT & number of shafts & 1 \\
\hline $\begin{array}{l}(\operatorname{NCOMP}(J) \\
\quad J=1, \operatorname{NSHAFT})\end{array}$ & number of compressors on each shaft & 1 (for $\mathrm{J}=1$ only) \\
\hline $\begin{array}{l}((\operatorname{ETAC}(\mathrm{I}, \mathrm{J}) \\
\mathrm{I}=1, \operatorname{NCOMP}(\mathrm{J})) \\
\mathrm{J}=1, \operatorname{NSHAFT})\end{array}$ & $\begin{array}{l}\text { compressor efficiency (See IETAC and } \\
\text { KPOLY. Only ETAC }(1,1) \text { need be } \\
\text { input if IETAC }=0 . \text { ) }\end{array}$ & -- \\
\hline IETAC & $\begin{array}{l}\text { compressor efficiency value indicator: } \\
0 \text { - all } \operatorname{ETAC}(\mathrm{I}, \mathrm{J})=\operatorname{ETAC}(1,1) \\
1 \text { - each } \operatorname{ETAC}(\mathrm{I}, \mathrm{J}) \text { must be input }\end{array}$ & 0 \\
\hline KPOLY & $\begin{array}{l}\text { compressor and turbine efficiency } \\
\text { type indicator: } \\
0 \text { - overall (isentropic) efficiency } \\
1 \text { - polytropic efficiency }\end{array}$ & 1 \\
\hline $\mathrm{RCMN}$ & $\begin{array}{l}\text { minimum value of overall compression } \\
\text { ratio }\end{array}$ & -- \\
\hline RCDEL & increment in overall compression ratio & -- \\
\hline RCMAX & $\begin{array}{l}\text { maximum value of overall compression } \\
\text { ratio (Calculations made at incre- } \\
\text { ments of RCDEL for each compres- } \\
\text { sion ratio starting at RCMIN and } \\
\text { ending at RCMAX.) }\end{array}$ & --- \\
\hline
\end{tabular}


Variable

(RCSHSP(J), $\mathrm{J}=1$, NSHAFT)

$((\mathrm{RCCOSP}(\mathrm{I}, \mathrm{J})$, $\mathrm{I}=1, \operatorname{NCOMP}(\mathrm{J}))$ $\mathrm{J}=1$, NSHAFT)

((ICOOL(I, J), $\mathrm{I}=1, \operatorname{NCOMP}(\mathrm{J}))$ $\mathrm{J}=1$, NSHAFT)

((RINT)(I, J), $\mathrm{I}=1, \operatorname{NCOMP}(\mathrm{J}))$ $\mathrm{J}=1$, NSHAFT)

IRINT

$$
\begin{gathered}
((\mathrm{TINT}(\mathrm{I}, \mathrm{J}), \\
\mathrm{I}=1, \operatorname{NCOMP}(\mathrm{J})) \\
\mathrm{J}=1, \operatorname{NSHAFT})
\end{gathered}
$$

ITINT

WLAOWA

(NTURB(J), $\mathrm{J}=1$, NSHAFT)

((IBURN(I, J), $\mathrm{I}=1, \operatorname{NTURB}(\mathrm{J}))$ $\mathrm{J}=1$, NSHAFT)
Description

Preset value

shaft compression ratio factor, fractional

1.0 (for $\mathrm{J}=1$ only) power of overall compression ratio (Sum of RCSHSP $(J)$ must equal 1.0.)

compressor compression ratio factor for

1.0 (for $\mathrm{I}=1, \mathrm{~J}=1$ only) each shaft, fractional power of shaft compression ratio (Sum of RCCOSP (I, J) must equal 1.0 for each J.)

intercooling indicator:

0 (for all I, J)

0 - no intercooling

1 - intercooling

intercooler total pressure recovery (Input only for those I, J having ICOOL(I, J) $=1$. See IRINT. Only RINT $(1,1)$ need be input if IRINT=0.)

intercooler total pressure recovery value 0 indicator:

0 - all $\operatorname{RINT}(\mathrm{I}, \mathrm{J})=\operatorname{RINT}(1,1)$

1 - each RINT(I, J) must be input

intercooler exit temperature, $\mathrm{K}\left({ }^{\mathrm{O}} \mathrm{R}\right)$ (Input --only for those I, J having ICOOL(I, J)=1. See ITINT. Only TINT $(1,1)$ need be input if ITINT=0.)

intercooler exit temperature value

0 indicator:

0 - all $\operatorname{TINT}(\mathrm{I}, \mathrm{J})=\operatorname{TINT}(1,1)$

1 - each TINT(I, J) must be input

recuperator leakage flow, fraction of

0.0 inlet flow

number of turbines on each shaft

1 (for $\mathrm{J}=1$ only)

reheating indicator:

1 (for $\mathrm{I}=1, \mathrm{~J}=1$ only)

0 - no reheating

0 (for all other I, J)

1 - reheating 


\begin{tabular}{|c|c|c|}
\hline Variable & Description & Preset value \\
\hline $\begin{array}{l}((\operatorname{ETAB}(\mathrm{I}, \mathrm{J}) \\
\mathrm{I}=1, \mathrm{NTURB}(\mathrm{J})) \\
\mathrm{J}=1, \mathrm{NSHAFT})\end{array}$ & $\begin{array}{l}\text { burner efficiency (Input only for those I, J having } \\
\text { IBURN }(\mathrm{I}, \mathrm{J})=1 \text {. See IETAB. Only } \operatorname{ETAB}(1,1) \\
\text { need be input if IETAB }=0 \text {.) }\end{array}$ & --- \\
\hline IETAB & $\begin{array}{l}\text { burner efficiency value indicator: } \\
0 \text { - all } \operatorname{ETAB}(\mathrm{I}, \mathrm{J})=\operatorname{ETAB}(1,1) \\
1 \text { - each } \operatorname{ETAB}(\mathrm{I}, \mathrm{J}) \text { must be input }\end{array}$ & 0 \\
\hline $\begin{array}{l}((\text { RBURN }(\mathrm{I}, \mathrm{J}) \\
\mathrm{I}=1, \mathrm{NTURB}(\mathrm{J})) \\
\mathrm{J}=1, \mathrm{NSHAFT})\end{array}$ & $\begin{array}{l}\text { burner total pressure recovery (Input only for } \\
\text { those I, J having IBURN }(\mathrm{I}, \mathrm{J})=1 \text {. See IRBURN. } \\
\text { Only } \operatorname{RBURN}(1,1) \text { need be input if IRBURN=0.) }\end{array}$ & --- \\
\hline IRBURN & $\begin{array}{l}\text { burner total pressure recovery value indicator: } \\
0 \text { - all } \operatorname{RBURN}(\mathrm{I}, \mathrm{J})=\operatorname{RBURN}(1,1) \\
1 \text { - each } \operatorname{RBURN}(\mathrm{I}, \mathrm{J}) \text { must be input }\end{array}$ & 0 \\
\hline $\begin{array}{l}((\mathrm{TTI}(\mathrm{I}, \mathrm{J}) \\
\mathrm{I}=1, \operatorname{NTURB}(\mathrm{J})) \\
\mathrm{J}=1, \mathrm{NSHAFT})\end{array}$ & $\begin{array}{l}\text { burner exit (turbine inlet) temperature, } K\left({ }^{\circ} R\right) \\
\text { (Input only for those } 1, J \text { having IBURN }(I, J)=1 \text {. } \\
\text { See ITTI. Only } \operatorname{TTI}(1,1) \text { need be input if } \\
\text { ITTI=0.) }\end{array}$ & --- \\
\hline ITTI & $\begin{array}{l}\text { burner exit temperature value indicator: } \\
0 \text { - all } \operatorname{TTI}(\mathrm{I}, J)=\operatorname{TTI}(1,1) \\
1 \text { - each } \operatorname{TTI}(\mathrm{I}, J) \text { must be input }\end{array}$ & 0 \\
\hline HVF & $\begin{array}{l}\text { lower heating value of fuel at temperature } \mathrm{TR} \text {, } \\
\mathrm{J} / \mathrm{kg}(\mathrm{Btu} / \mathrm{lb})\end{array}$ & 18640 . \\
\hline TR & $\begin{array}{l}\text { reference temperature for fuel heating value, } \\
\quad K\left({ }^{\circ} R\right)\end{array}$ & 760. \\
\hline HOC & mass ratio of hydrogen to carbon in fuel & 0.16786 \\
\hline ITF & $\begin{array}{l}\text { indicator for fuel temperature entering burner: } \\
0 \text { - fuel enters burner at temperature TR } \\
1 \text { - fuel enters burner at temperature TF } \\
\geq 10 \text { - fuel enters burner at temperature } \\
\text { calculated from fuel compression work } \\
\text { (Second digit indicates number of inter- } \\
\text { cools back to TFIN during fuel com- } \\
\text { pression. In this case fuel compression } \\
\text { power is subtracted from gross shaft } \\
\text { power output.) }\end{array}$ & 0 \\
\hline
\end{tabular}


le

BF

CF

TFIN

PRFIN

ETACF

MWF

((ETAT(I, J),

$\mathrm{I}=1, \operatorname{NTURB}(\mathrm{J}))$

$\mathrm{J}=1$, NSHAFT)

IETAT

(POWFAC(J), $\mathrm{J}=1$, NSHAFT -1 )

((TSPLIT(I, J), $\mathrm{I}=1, \operatorname{NTURB}(\mathrm{J}))$

$J=1$, NSHAFT)
Description

$\underline{\text { Preset value }}$

temperature of fuel entering burner

$K\left({ }^{\circ} R\right.$ ) (Input only when ITF $=1$.)

constant $A_{f}$ in fuel heat capacity equa-

tion (eq. (C1)), J/(kg)(K) $\left(\mathrm{Btu} /(\mathrm{lb})\left({ }^{\mathrm{O}} \mathrm{R}\right)\right)$

(Input only when ITF $>0$.)

constant $B_{f}$ in fuel heat capacity equation

(eq. (C1)), J/(kg) $\left(\mathrm{K}^{2}\right)\left(\mathrm{Btu} /(\mathrm{lb})\left({ }^{0} \mathrm{R}^{2}\right)\right)$

(Input only when ITF $>0$.)

constant $\mathrm{C}_{\mathrm{f}}$ in fuel heat capacity equation

(eq. (C1)), J/(kg)( $\left.\mathrm{K}^{3}\right)\left(\mathrm{Btu} /(\mathrm{lb})\left({ }^{0} \mathrm{R}^{3}\right)\right)$

(Input only when ITF $>0$.)

temperature of fuel entering fuel compressor, $K\left({ }^{\circ} R\right)$ (Input only when ITF $\geq 10$.)

ratio of pressure of fuel entering fuel com- 1.0 pressor to ambient pressure (Input only when ITF $\geq 10$.)

fuel compressor polytropic efficiency

(Input only when ITF $\geq 10$.)

fuel molecular weight (Input only when ITF $\geq 10$.)

turbine efficiency (See IETAT and KPOLY. Only $\operatorname{ETAT}(1,1)$ need be input if IETAT = 0.)

turbine efficiency value indicator:

0 - all $\operatorname{ETAT}(I, J)=\operatorname{ETAT}(1,1)$

1 - each $\operatorname{ETAT}(I, J)$ must be input

output power factor for all shafts other than low-pressure shaft (J=NSHAFT), ratio of total shaft power to compressor power (Not used when NSHAFT=1.)

turbine work factor for each shaft (For shafts other than low-pressure shaft, TSPLIT specifies power of each turbine as fraction of shaft power; for lowpressure shaft ( $\mathrm{J}=$ NSHAFT), TSPLIT
0

1.0 (for all J)

1.0 (for $I=1, J=1$ only) 
Variable

((WCAOWA(I, J), $\mathrm{I}=1, \operatorname{NTURB}(\mathrm{J}))$ $\mathrm{J}=1$, NSHAFT)

ITCOOL

TCOOL

R65

ER

R32

R76

RSTEX

ETAETA

TTOL

KOUT

IU
Description

Preset value

specifies pressure ratio for each turbine as

fractional power of shaft pressure ratio. Sum

of TSPLIT(I, J) must equal $1.0^{\circ}$ for each J.)

turbine coolant flow, fraction of inlet flow

0.0 (for all I, J)

turbine coolant temperature indicator:

0

0 - turbine coolant temperature equals last compressor exit temperature

1 - turbine coolant temperature equals input TCOOL

turbine coolant temperature, $\mathrm{K}\left({ }^{\mathrm{O}} \mathrm{R}\right)$ (Input only when ITCOOL $=1$.)

turbine exit diffuser total pressure recovery

1.0

recuperator effectiveness

0.0

recuperator cold-side total pressure recovery

1.0

recuperator hot-side total pressure recovery

1.0

cycle exit static-to-total pressure ratio

1.0

shaft power conversion efficiency

1.0

temperature tolerance for iterative calcula-

0.1

tions, $\mathrm{K}\left({ }^{\mathrm{O}} \mathrm{R}\right)$

output indicator:

0

0 - output for each cycle point consists of overall performance only

1 - output for each cycle point consists of overall performance plus all internal temperatures, pressures, and flow rates

units indicator:

2

1 - SI units

2 - U.S. customary units

Input data for NAMELIST input begins with a $\$$ in the second location on a new line, immediately followed by the NAMELIST name, which is INPUT for this program, immediately followed by one or more blank characters. Any combination of three types 
of data items may then follow. The data items must be separated by commas. If more than one line is needed for the input data, the last item on each line, except the last line, must be a number followed by a comma. The first location on each line should always be left blank since it is ignored. The end of a group of data items is signaled by a $\$$ anywhere except in the first location of a line. The form that data items may take is:

(1) Variable name = constant, where the variable name may be an array element or a simple variable name. Subscripts must be integer constants.

(2) Array name = set of constants separated by commas where $k *$ constant may be us ed to represent $k$ consecutive values of a constant. The number of constants must be equal to or less than the number of elements in the array. This results in the set of constants being placed in consecutive array elements, starting with the first element of the array.

(3) Subscripted variable = set of constants separated by commas where, again, $\mathrm{k} *$ constant may be used to represent $\mathrm{k}$ consecutive values of a constant. This results in the set of constants being placed in consecutive array elements, starting with the element designated by the subscripted variable.

Illustrative example. - The cycle being used as the illustrative example for input and output is shown in figure 6 . It is a two-shaft recuperated system with four intercoolers and three reheaters. The arrangement of components along with the proper subscripts for each component are shown in figure 6. Also shown in the figure are all temperatures, pressures, flows, and component performance parameters required as program input. The fuel is a gas composed of 80 percent (by volume) methane and 20 percent ethane. The fuel properties required as program input are found in any appropriate reference book. It is desired to compute cycle thermodynamic performance for overall compression ratios of 5 to 100 in increments of 5 .

The program input for this illustrative example is presented in table $I$. It is assumed that the user is familiar with the rules for NAMELIST input, some of which were presented previously, and with the order of array storage. A FORTRAN instruction or reference manual should be consulted for complete information of this type. Each line of the input form shown in table I represents one data card. The output corresponding to this sample input is described in the following section.

\section{Output}

The program output consists of a description of the input and the computed results. This section presents normal output. Error message output is described in the next section.

Table II presents the output that corresponds to the input shown in table I for the illustrative example. The first part of the output is the description of the input, which 
is in narrative form. The first line gives the number of shafts and the ambient temperature and pressure. The next line presents the inlet and diffuser pressure recoveries and the exit static-to-total pressure ratio. The third line gives the recuperator effectiveness and pressure recoveries. The next three lines present all the fuel-related input.

All input parameters associated with the intercoolers, compressors, burners, and turbines are then presented in shaft groupings. For each shaft the top line presents the shaft number, number of compressors; fraction of overall compression, and number of turbines. There is a line for each compressor, giving its fraction of shaft compression and its efficiency. If there is an intercooler preceding the compressor, there is a line of output preceding the compressor line and giving the intercooler exit temperature and pressure recovery. Then there is a line for each turbine on the shaft, giving the turbine power or expansion fraction and the turbine efficiency. If there is a burner preceding the turbine, there is a line of output preceding the turbine line and giving the burner exit temperature, efficiency, and pressure recovery. If the turbine is cooled, there is a line of output giving the amount of coolant flow. After this information is presented for each shaft, there is finally a line of output giving the shaft-power conversion efficiency and specifying the nature of the turbomachinery efficiencies.

After presentation of all the input information, the computed results are then printed. Since KOUT $=0$ (preset value not altered by input), the computed results that are printed include the overall performance only. There is one line of results output for each compression ratio. The results output includes the compression ratio, specific power output (both in $\mathrm{kW}$ and $\mathrm{hp}$ ), specific fuel consumption, cycle efficiency, and fuel-compression power.

If the input had specified that KOUT $=1$, the results output would include all internal temperatures, pressures, and flow rates in addition to the overall performance. An example of this detailed output is shown in table III, which gives the results output for a compression ratio of 50. There is one line of output for each compressor and each turbine as well as for each side of the recuperator. The lines of output are in flow sequence. For the compressors and turbines, the shaft and component numbers are given, followed by a "NO" or "YES" to specify whether there is an intercooler preceding the compressor or a burner preceding the turbine. Then, the next five columns give the inlet flow, pressure, and temperature, and the exit pressure and temperature for each component. For the turbines the temperature and flow after coolant mixing are given in the next two columns. This same information is provided for mixing of any leakage flow in the recuperator. The last column gives the specific work for each compressor and turbine. The overall performance is presented to the right of the table of detailed output. 
The program contains five output messages indicating the nonexistence of a solution satisfying the specified input requirements. These messages are presented in this section, and their causes are discussed.

(1) COMPRESSOR EXIT TEMP (XXXX. X) GREATER THAN TURBINE INLET TEMP (XXXX.X) - This message is caused by the computed exit temperature $T_{2}^{\prime}$ from the last compressor $\left(C_{11}\right)$ being greater than the primary burner $\left(B_{11}\right)$ exit temperature $T_{4}^{\prime}$. It indicates that the overall compression ratio is too high and/or the burner exit temperature is too low. After the message is printed, the program calls for another data set.

(2) TURBINE-SYSTEM EXIT PRESSURE (XXX. XX) GREATER THAN TURBINE EXIT PRESSURE PTT0(I, J)=XXX. XX - This message is caused by the exit pressure for any turbine in the system being less than the available pressure $\mathrm{p}_{5}^{\prime}$ at the last turbine exit. It indicates that the overall compression ratio is too low for the cycle to be selfsustaining in view of the compressor and turbine inefficiencies and the pressure losses in the other components. If the compression ratio is not particularly low, one of the input efficiencies or pressure recoveries could be excessively low. After the message is printed, the program increments the overall compression ratio to the next higher value and proceeds with the new calculation.

(3) RECUPERATOR HOT GAS INLET TEMP (XXXX.X) COLDER THAN COLD GAS INLET TEMP (XXXX. X) - This message is caused by the last turbine exit temperature $T_{5}^{\prime}$ being lower than the last compressor exit temperature $T_{2}^{\prime}$ with a recuperator in the system. It indicates that the overall compression ratio is too high to provide a temperature potential for recuperation. After the message is printed, the program calls for another data set.

(4) TURBINE POWER LESS THAN COMPRESSOR POWER ON SHAFT J - This message is caused by the turbine power for the low-pressure shaft (J=NSHAFT) being less than the power required to drive the compressors on that shaft. The basic causes for this condition are the same as for error message (2), as is the program operation sequence.

(5) OXYGEN USED UP IN BURNER I ON SHAFT $J$ - This message is caused by the fuel-air ratio in the flow leaving a burner being greater than the stoichiometric fuel-air ratio. It indicates that all the oxygen in the inlet air was used up before all the required burning occurred. This can be caused by overall compression ratio being too low or burner-exit temperature being too high. After the message is printed, the program increments the overall compression ratio and proceeds with the new calculation. 


\section{PROGRAM DESCRIPTION}

This computer program consists of main program MULTI, subroutine FUEL, and a set of combustion-gas thermodynamic-property subprograms containing the six functions $\mathrm{CP}, \mathrm{H}, \mathrm{T} 2 \mathrm{H}, \mathrm{S}, \mathrm{T} 2 \mathrm{~S}$, and HF and subroutine THERMO. The entire program is written in IBM 7090/7094 FORTRAN IV language. In this section, the functions of the main and subprog rams are described, the program variables are defined, and the program listing is presented.

\section{Main Program MULTI}

Main program MULTI performs all input and output operations, all logic associated with the shaft and component arrangements, and all computations except those directly using the thermodynamic properties of the fuel and of the combustion gas.

Program variables. - The variables used in MULTI are defined as follows:
ABSBF
absolute value of $B F$
ABSCF
absolute value of $C F$
AF
constant $A_{f}$ in eq. (C1)
BF
constant $B_{f}$ in eq. (C1)
CF
constant $\mathrm{C}_{\mathrm{f}}$ in eq. (C1)
$\operatorname{DELHC}(\mathrm{I}, \mathrm{J}) \quad$ compressor specific work
DELHF
fuel compression specific work
$\operatorname{DELHIN}(\mathrm{I}, \mathrm{J}) \quad$ intercooler heat removal per pound of flow
DELHSH(J) sum of compressor specific work for shaft $J$
$\operatorname{DELHT}(\mathrm{I}, \mathrm{J}) \quad$ turbine specific work
DHID
turbine ideal specific work
DHL
recuperator leakage mixing heat balance term
DHM
turbine coolant mixing heat balance term
DHR
recuperator heat balance term
DLHC
overall sum of compressor specific work
ER
recuperator effectiveness
$\operatorname{ETAB}(I, J) \quad$ burner efficiency
$\operatorname{ETAC}(\mathrm{I}, \mathrm{J}) \quad$ compressor efficiency 


\begin{tabular}{|c|c|}
\hline ETACF & fuel compressor efficiency \\
\hline ETACY & cycle efficiency \\
\hline ETAETA & shaft power conversion efficiency \\
\hline $\operatorname{ETAT}(I, J)$ & turbine efficiency \\
\hline EXP1 & data statement word EXPAN for output use \\
\hline EXP2 & data statement word SION for output use \\
\hline FA & fuel-air ratio \\
\hline $\mathrm{FBOA}(\mathrm{I}, \mathrm{J})$ & fuel-air ratio addition in burner \\
\hline FLPOKW & fuel compression power \\
\hline $\operatorname{FOATI}(I, J)$ & fuel-air ratio at turbine inlet \\
\hline $\operatorname{FOATOM}(I, J)$ & fuel-air ratio after turbine coolant mixing \\
\hline FOA5 & fuel-air ratio at station 5 \\
\hline FOA6 & fuel-air ratio at station 6 \\
\hline FOA 7 & fuel-air ratio at station 7 \\
\hline FOA8 & fuel-air ratio at station 8 \\
\hline FSTOIC & stoichiometric fuel-air ratio \\
\hline FUELPO & fuel compression power \\
\hline $\mathrm{H}$ & $\begin{array}{l}\text { function defined by eq. (B7), see Combustion-Gas Thermodynamic } \\
\text { Property Subprograms }\end{array}$ \\
\hline $\mathrm{HF}$ & $\begin{array}{l}\text { function defined by eq. (B10), see Combustion-Gas Thermodynamic } \\
\text { Property Subprograms }\end{array}$ \\
\hline HFF & fuel enthalpy relative to reference temperature \\
\hline HOC & mass ratio of hydrogen to carbon in fuel \\
\hline HVF & lower heating value of fuel \\
\hline I & dummy index \\
\hline IBURN(I, J) & reheating indicator, see Input section \\
\hline IC & compressor number index \\
\hline $\operatorname{ICOOL}(\mathrm{I}, \mathrm{J})$ & intercooling indicator, see Input section \\
\hline IETAB & burner efficiency value indicator, see Input section \\
\hline IETAC & compressor efficiency value indicator, see Input section \\
\hline
\end{tabular}


IETAT

IRBURN

IRINT

IS

IT

ITCOOL

ITF

ITINT

ITTI

IU

J

JJ

JJJ

KOUT

KPOLY

L

M

MINUS

MW

MWF

N

$\operatorname{NCOMP}(J)$

NS

NSHAFT

NTURB(J)

OF F

ON

OVHP

OVPOKW turbine efficiency value indicator, see Input section

burner total-pressure recovery value indicator, see Input section intercooler total-pressure recovery value indicator, see Input section shaft number index

turbine number index

turbine coolant temperature indicator, see Input section

burner-inlet fuel temperature indicator, see Input section

intercooler-exit temperature value indicator, see Input section

burner-exit temperature value indicator, see Input section

units indicator, see Input section

dimensional constant

turbine number index for last turbine on shaft

number of turbines on shaft number NSHAFT

output indicator, see Input section

compressor and turbine efficiency indicator, see Input section

$\left\{\begin{array}{l}\text { dummy index } \\ \text { turbine number index }\end{array}\right.$

dummy index

data statement word for minus sign for output use

combustion-gas molecular weight function, eq. (B15)

fuel molecular weight

index for number of turbines on shaft

number of compressors on each shaft

number of shafts minus one

number of shafts

number of turbines on each shaft

data statement word NO for output use

data statement word YES for output use

net output power

net output power 
P HP

PKW

PLUS

PNC2

POWFAC(J)

POWSH(J)

POWT(I, J)

POWTSH

POW1

POW2

PSI

PRFIN

PRSH

$\operatorname{PRT}(\mathrm{I}, \mathrm{J})$

PSC

PST

PSO

PT

$\operatorname{PTCI}(\mathrm{I}, \mathrm{J})$

PTCO(I, J)

PTTI(I, J)

PTTO(I, J)

$\operatorname{PTTOM}(\mathrm{I}, \mathrm{J})$

PT0

PT1

PT2

PT3

PT5

PT6

PT7 data statement word HP for output use data statement word KW for output use data statement word for plus sign for output use data statement word N/CM2 for output use shaft output power factor, see Input section total power for each shaft except for shaft number NSHAFT shaft power for each turbine total power for shaft number NSHAFT data statement word POW for output use data statement word ER for output use data statement word PSIA for output use ratio of fuel inlet pressure to ambient pressure total turbine expansion ratio for shaft number NSHAFT expansion ratio for each turbine on shaft number NSHAFT value of function $\Phi$ in eq. (9) or (12) value of function $\Phi$ in eq. (34) or (35) ambient pressure total pressure compressor inlet total pressure compressor exit total pressure turbine inlet total pressure turbine exit total pressure turbine exit total pressure after coolant mixing total pressure at station 0 total pressure at station 1 total pressure at station 2 total pressure at station 3 total pressure at station 5 total pressure at station 6 total pressure at station 7 
total pressure at station 8

QF

$\mathrm{R}$

RBURN(I, J) burner total pressure recovery

RBURNT

$\mathrm{RC}$

$\mathrm{RCCOSP}(\mathrm{I}, \mathrm{J})$

RCDEL

RCMAX

RCMIN

$\operatorname{RCOMP}(\mathrm{I}, \mathrm{J})$

RCSHFT $(J)$

$\operatorname{RCSHSP}(J)$

$\operatorname{RINT}(\mathrm{I}, \mathrm{J})$

RSTEX

R10

R32

R65

R76

$\mathrm{S}$

SFC

SHPOBT

SIGNBF

SIGNCF

TCOOL

TEST

TF

TFIN

TINT(I, J)

gas constant

overall compression ratio

inlet total pressure recovery

Property Subprograms

specific fuel consumption

net output shaft power

turbine coolant temperature

intercooler-exit temperature total heat input to cycle: .

product of all RBURN(I, J) for shaft number NSHAFT

compressor compression ratio factor for each shaft, see Input section increment in overall compression ratio

maximum value of overall compression ratio

minimum value of overall compression ratio

compression ratio for each compressor

compression ratio for each shaft

shaft compression ratio factor, see Input section

intercooler total pressure recovery

cycle-exit static-to-total pressure ratio

recuperator cold-side total pressure recovery

diffuser total pressure recovery

recuperator hot-side total pressure recovery

function defined by eq. (B12), see Combustion-Gas Thermodynamic

output word set equal to PLUS or MINUS as appropriate

output word set equal to PLUS or MINUS as appropriate

value used to test for maximum compression ratio

temperature of fuel entering burner

temperature of fuel entering fuel compressor 
TPK

TPK1

TPK2

TPR

TPR1

T.PR2

TR

TSPLIT(I, J)

TS0

TT

TTCI(I, J)

$\operatorname{TTCO}(\mathrm{I}, \mathrm{J})$

TTCOID(I, J)

TTI(I, J)

TTOL

TTTI(I, J)

TTTO(I, J)

TTTOID(I, J)

TTTOM(I, J)

TT0

TT1

TT2

TT3

TT3PRE

TT5

TT6

TT7

TT8

TYPEF

TYPEFP data statement word $\mathrm{K}$ for output use

data statement word KELV for output use

data statement word IN for output use

data statement word $\mathrm{R}$ for output use

data statement word RANK for output use

data statement word INE for output use

reference temperature for fuel heating value

turbine work factor for each shaft, see Input section

ambient temperature

total temperature

compressor-inlet total temperature

compressor-exit total temperature

compressor-exit ideal total temperature

burner-exit temperature

temperature tolerance for iterative calculations

turbine-inlet total temperature

turbine-exit total temperature

turbine-exit ideal total temperature

turbine-exit total temperature after coolant mixing

total temperature at station 0

total temperature at station 1

total temperature at station 2

total temperature at station 3

previous value of total temperature at station 3

total temperature at station 5

total temperature at station 6

total temperature at station 7

total temperature at station 8

output word set equal to TYPEFP or TYPEFI as appropriate data statement word POLY for output use 
TYPEFI

$\mathrm{T} 2 \mathrm{H}$

T2S

W

WAIRT

WAIR2

WAIR5

WAIR6

WAIR7

WAIR8

WARTOM(I, J)

WBTU

WCAOWA(I, J)

WCAWA

WF(I, J)

WFTOT

WGM

WJLS

WKG

W LAOWA

W LB

WT

WTI(I, J)

WTOM(I, J)

W0

W1

W2

W3 data statement word ISEN for output use

temperature satisfying function $\mathrm{H}$ value, see Combustion-Gas Thermodynamic Property Subprograms

temperature satisfying function $\mathbf{S}$ value, see Combustion-Gas Thermodynamic Property Subprograms

ambient air absolute humidity

airflow rate

airflow rate at station 2

airflow rate at station 5

airflow rate at station 6

airflow rate at station 7

airflow rate at station 8

airflow rate at turbine exit after coolant mixing

data statement word BTU for output use

coolant flow fraction to each turbine

total coolant flow fraction

fuel flow rate to each burner

total fuel flow rate

data statement word GM for output use

data statement word JLS for output use

data statement word KG for output use

recuperator leakage flow fraction

data statement word $\mathrm{LB}$ for output use

gas flow rate

gas flow rate at turbine inlet

gas flow rate at turbine exit after coolant mixing

gas flow rate at station 0

gas flow rate at station 1

gas flow rate at station 2

gas flow rate at station 3 
gas flow rate at station 5

W6 gas flow rate at station 6 gas flow rate at station 7 gas flow rate at station 8

X1 output word set equal to POW1 or EXP1 as appropriate X2 output word set equal to POW2 or EXP2 as appropriate output word set equal to TPR1 or TPK1 as appropriate output word set equal to TPR2 or TPK2 as appropriate output word set equal to TPR or TPK as appropriate output word set equal to PPSI or PNC2 as appropriate output word set equal to WLB or WKG as appropriate output word set equal to PHP or PKW as appropriate output word set equal to WLB or WGM as appropriate output word set equal to WBTU or WJLS as appropriate output word set equal to ON or OFF as appropriate

Program listing. - The FORTRAN listing for main program MULTI is as follows:

C

c

C

c.

THERMODYNAMIC CYCLE ANALYSIS FOR MIJLTISHAFT POWER SYSTEM WITH YUL TIPLE INTERCODLS ANO REHEATS

COMMON/CFUEL /AF, BF, CF, TFIN, TF, ETACF, I TF, RC, HE F, TR, DELHF, MW F, DRFIN COMMON HOC, TTOL, W

REAL J,NW, MWF, MINUS

DIMEN SION WCAOWA $(5,5), I C O O L(5,5), \operatorname{IBURN}(5,5), \operatorname{RCCCS} P(5,5)$, TS PLIT $(5,5$ 1), RRIJRN $(5,5), \operatorname{TTCO}(5,5), \operatorname{PTC}(5,5), \operatorname{TINT}(5,5), \operatorname{TTCI}(5,5), \operatorname{PTCI}(5,5)$, 2R INT $(5,5)$, DELHIN $(5,5), F C D M P(5,5), \operatorname{TTCOID}(5,5)$, DELHC $(5,5), E T A C(5,5)$, 3T TI (5, 5), TTTOM $(5,5)$, P TTOM $(5,5)$, WT $] M(5,5)$, WART DM $(5,5)$, FRATOM(5, 5), 4PTTI(5, 5$), T T T I(5,5), F B \cap A(5,5), E T A H(5,5), F \cap A T I(5,5)$, WF $(5,5), W T I(5,5$ 5), P OWT $(5,5)$, กELHT $(5,5)$, FTAT $(5,5)$, TTTOID $(5,5)$, PTT $7(5,5)$, PRT $(5,5)$, 6TTTO( 5,5$)$, POWFAC ( 5), NCOMD (5), NTURB (5), RCSHSP (5), FCSHFT (5), DELHSHI 5 7), PกW SH (5)

C

NAMEL IST/INPIIT/TSO,PSO,FIO,ETAC, WCAOWA, ER, R 32, HVF, TR, ETAR, RINT, IRBURA, TTI, ETA T, ETAETA, W, I CODL, I BURN, I TC OOL, I IE TAC, IETAT, IETAB, 2PDWFAC, NSHAFT, NCOMO, YTURB, RCSHSP, RC COSP, TSPLI T. ITT I , I I INT, HCC, R65, 3R 76, T TCL, TINT, RCMIN, RCDEL, RCMAX, TCOOL, TF, AF, BF, CF, ETACF, MNF, TFIN, 4IRBIIRN, IR INT, ITF, KUIJT, KPILY, WLACWA, PRFIN, PSTEX, III

$M W(F)=(1.0+F+W) /(.0345 ? 2+(F /(1.0+H O C)) *(.24832 * H n C)+W / 19.016)$

$R(F)=1 \leq 45 . / M W(F)$

DATA PLUS,MINIIS/IH+, LH-

RATA PCh1,PחW2,EXP1, EXP?/5H POW,5HEP ,5HEXPAN,5HSION I

DATA TYDEFP, TYOEFI/5H POLY, 5H ISENI 
กATA UA, TIFF/5H YES, SH NOI

)ATA TPF 1, TPQ 2, TPK1,TPK2, TPR, TPK/4HKANK, 3HINE, 4HKELV, 3HIV, LHR, LHK I/, WGM, hRTU, W.J LS/ ZHS, M, 3HRTII, 3H.JLSI

חATA FDS!, PHE $2 / \mathrm{CH}$ PSIA, SH N/CM2/

ПATA WLR, WKG/ ZHLB, 2HKG/, PHP, PKW/2H!P, 2HKWI

r.

C.

C

\section{INITIAL ITATION}

$T S O=51 \varepsilon .7$

D SO $=14.696$

$W=0.0$

ETAETA $=1.0$

R $10=1$.

D) $72 \mathrm{~L}=1,5$

Dก $71 N=1,5$

WCAOWA $(L, M)=0.0$

$\operatorname{ICOOL}(L, M)=0$

$71 \operatorname{IBUPN}(\mathrm{L}, M)=0$

72 PกW

NSHAFT $=1$

NC JMP ( ) I = 1

$V \operatorname{TURP}(1)=1$

RCSHSP $(1)=1$.

$\operatorname{RCCOSP}(1,1)=1$.

TSPLIT $(1,1)=1$.

I RIIRN $(1,1)=1$

ITT I = C

$I T I N T=C$

I TCOOL $=\mathrm{C}$

I ETAC $=C$

I ET $\Delta T=0$

I ETA $=\mathrm{C}$

IR. INT $=\mathrm{C}$

I R RUR: $\mathrm{N}=\mathrm{C}$

$K \cap ! S T=0$

$K P O L Y=1$

WL $A O W A=0.0$

I T $F=0$

$E R=C . O$

R $32=1$.

$\mathrm{H} \cap \mathrm{C}=.16796$

$H V F=18 \epsilon 40$.

$T R=760$.

PRF IN $=1.0$

R. $65=1$.

R $75=1$.

R STEX $=1$.

I U $=2$

$j=778$.

TTOL $=.1$

1 IF (IU.EO.2) 6.0 TO 73

T SU $=T S C / 1.8$

Di) $76 \quad I=1$, NSHAFT

I I $=N C \cap N P$ ( I )

กก $74 L=1$, II

$74 T I N T(L, I)=T I N T(L, I) / 1,8$

$I J=N T U P R(I)$

DIJ $75 \mathrm{~L}=1, \mathrm{IJ}$

$75 \mathrm{TTI}(\mathrm{L}, \mathrm{I})=\mathrm{TTI}(\mathrm{I}, 1) / 1 . \mathrm{P}$ 
76 CONTINLE

$H V F=H V F=1055.87 \% .45355237$

$T R=T R / 1.8$

$T F=T F / 1.9$

$\Delta F=A F * 10.55 .37 / .45359237 * 1.3$

$B F=B F * 1055.87 / .45359 \geq 37 * 1.8 * 1.9$

$C F=C F * 1055.87 / .45359237 * 1.8 * 1.8 * 1.8$

IFI ITF.Gi..10) TFIN! $=$ TF IN/1.8

IF(ITRRGL.ED. 1) TCONL =TCINL/1.8

73 PEAD (5, INIPUT)

$\times 3=T P R 1$

$\times 4=T D R .2$

$\times 5=T F R$

$X 6=P P S I$

$\times 7=W I R$

$\times 8=P H P$

$X 9=W L R$

$X 10=$ WRTII

IF( IU.EG.2) r. O TO 7

$\times 3=T P K 1$

$\times 4=T P K 2$

$\times 5=T P K$

$X 6=P N C 2$

$\times 7=W K r$

$X 8=P K W$

$X 9=W G M$

$X 10=$ WJIS

7 TEST $=$ R.CMAX+. 1 * RCDEL

FSTOIC $=.2314 *(1 .+H \cap C) /(2.6644+7.9365 * \mathrm{HOC})$

IF( ITF.EO.O) TF $=$ TP.

$J J J=N T U P R$ ( $M$ SHAFT)

$W C A W A=C . O$

PRIJRNT $=1.0$

Dก $13 N=1, N S H A F T$

$L=N C \cap M P(M)$

I $F(L . E Q .0)$ GJ TO 12

Dก $11 \quad I=1, L$

IF( ICOCLII,M) .EO.0) SO TO 11

IFIITIAT.LQ.0) TINT $(I, M)=\operatorname{TINT}(1,1)$

IF(IR.INT.FQ.0) RINT $(I, M)=\operatorname{RINT}(1,1)$

11 I $F($ IETAC,EO.O) ETAC $(I, M)=E$ TAC $(1,1)$

$12 N=N \operatorname{TUR} R(M)$

no $13 \quad I=1, N$

$W C A W A=$ WCAWA +WCACWA $(I, M)$

IF( IRUFN(I,M)..EO.OI GO TO 13

IF (IETAB.EQ.O) ETAB $(1, M)=E T A B(1,1)$

IF( IF. RLRN.FO.0) F:BIIRN $(T, M)=R B U R N(1,1)$

I $F(M$.EQ .NSHAFT) FBUFNT $=R B U E N T$ RRUR N $(I, M)$

IFI ITTI.EO.O) TTI $(I, M)=T T I(1,1)$

$\mathrm{C}$

13 IF( IETAT.FQ.0) ETAT $(I, M)=E T A T(1,1)$

C

C

WP. ITE INPIIT VALUES

WRITE $(E, 1000)$ NSHAFT, TSO, X3, X4, PSU, X5,R10,R65,

12 STEX, FR, F 32, F 76, WLAПWA, HVF, TF, X3, X4,HOC.

1000 FDRMATI IHL, IL, 54H-SHAFT POWEF SYSTEM OPERATING AT ANBIENT CONDITIO

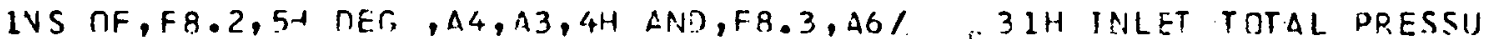
2RE PECOOVFFY =,F5.3,54-1, TIIFBINE EXHAUST IIIFIISER TOTAL PRESSURE

3RECOVFRY $=, F 5.3,29 \mathrm{H}$, EXIT STAT/TCT PRESS FATIC!=,F5.3, 
4TOTAL PEFSSURE PRCIVERY $=, F 5.3,35 \mathrm{H}$, HOT SINE TOT AL PRESSIJPE RECOVIR $5 Y=, F 5.2,14 \mathrm{H}$, BYPASS FLMW $=, F 6.4$

$5 / 20 \mathrm{H}$ FLEL HEATIN., VALUE $=, F 9.0,3 \mathrm{H}$ AT,F6.0,5H DEG, A4,A3, 12H, H

$6 / C, F A T I O=, F 7.5)$

IF( ITF.CF. 10) GO TO 42

41 WRITE: $(t, 1010)$ TF, $\times 3, \times 4$

1010 FDRMATIIH+,65X,23H, FIIEL ENTEFS BURNER AT,FG.0,5H DES, $44, \triangle 3 / 1$

IF(ITF.EO.O) GO TO 43

42 SIGNBF $=$ DLL:S

SISNC F $=$ MINUS

IF(BF.LT.0.O) SIGNBF=MINUS

IFICF. . E. O.0) SIGNCF $=$ PLUS

$\triangle B S B F=\triangle B S(B F)$

$\triangle B S C F=A B S(C F)$

WRITE $(6,1020)$ AF, SISNAF, ABSBF, SIGNCF, ABSCF

1020 FORMAT (13H FUEL GAS :P=,F9.4,1X,A1,1PE11.4,5H * $T, A 1, E 11.4,7 H *$ $1 T * 21$

IF( ITF.LT.10) GO Tก 43

WRITF $(6,1021)$ MWF, TF IN,PRF IN, ETACF

1021 FORMATI

1 FUEL MOL WGT $=$, OPF 7.3, $17 \mathrm{H}$ FUEL INLLT TEMP $=, F 5.0,25 \mathrm{H}$, FUEL INLET C

2OMPRESSIUN: $=, F 5.1,24 \mathrm{H}$, FUEL COMPRESSION EFF. $=, F 5.31$

43 Dก $50 \quad 1=1$, NSHAFT

I $S=N S+A F T+I-I$

$L=N \operatorname{COMP}($ IS $)$

$M=N T U R B$ (IS)

WRITE $(t, 1030)$ IS,L,RC SHSPIIS),M

1030 FORMATITHOSHAFT, $11,5 H$ HAS, I $1,24 H$ COMPRESSORS THAT SUPPLY,F7, 4,26

IH DF TOTAL COMPRESSION AND, II, $9 H$ TURBINESI

IF(IS.LT.NSHAFT) WRITE $(6,1040)$ POWFAC IS)

1040 FORMAT $(1 \mathrm{H+}, 81 \mathrm{X}$, I2HTHAT DELIVER,F7.4,25H * COMPRESSOR SHAFT POWER $)$

IF(L.EO.0) GO TO 46

Dก $45 \mathrm{LL}=1, \mathrm{~L}$

$I C=L+1-L L$

WRITE $(\epsilon, 1050)$

1050 FOPMAT(IH)

I F( ICOOL (IC, IS). NE.0) WR ITE $(6,1060)$ IC, TINT (IC, IS), $33, \times 4, R$ INT (IC, IS)

1060 FORMAT $16 X, 24 H F L O W$ ENTERING COMPRESSOR, I2, $13 \mathrm{H}$ IS CODLED TO, F6.0,5H

IDES, A $4, A 3,30 \mathrm{H}$ WITH TOTAL PRESSURE RECOVERY $=, F 5.31$

45 WRITE $(t, 1070)$ IC, RCCOSP(IC, IS), E TACIIC, IS)

1070 FORMAT $16 X, 10 H C O M P F E S S \cap R, I 2,9 H$ PROVINES,F7.4,38H HF SHAFT COMPRESSI

$10 N$ WITH EFFICIENC. $Y=, F 5.31$

46 DO $50 \quad I T=1, M$

WRITE $(\epsilon, 1050)$

I FI IBURN IT, IS ).NE . O) WPITE $(6,1080) I T, T T I(I T, I S), \times 3, \times 4, E T A B(I T$, IS I, IRRIJRN ( IT, IS)

1080 FQRMAT $(E X, 21 H F L O W$ ENTER ING TURBINE, I $2,13 \mathrm{H}$ IS HEATED TO,F7, $1,5 \mathrm{H}$ DEG

$1, A 4, A 3,29 H$ WITH COMBUSTION EFFICIENCY $=, F 5,3,29 H$ AND TDTAL PRESSU

2RE RECC VERY $=$,F5.3)

IF( IS-N SHAFT) $47,48,48$

$47 \times 1=P \cap W 1$

$\times 2=P \cap W_{2}$

GO TO 49

$48 \times 1=$ FXP 1

$\times 2=\operatorname{EXP} 2$

49 WR ITE $(t, 1090)$ IT, TSPLITIIT,I S), X1, X2, ETAT (IT, IS)

1090 FORMAT I X, 7HTURRINE, I 2, 9H PRDVIDES,F7.4,10H JF SHAFT, 245, 16HWITH LEFFIC, IENCY $=, 55.31$ 
IF(WCACWAI IT, IS).EO.0.0) GO TC 50

WRITE $(6,1100)$ IT, WCAOWA(IT, IS)

1100 FORMAT $16 X, 7 H T I R B I M E, I 2,15 H$ IS CONLEO WITH,F7.4,24H CF CCMPRESSOR E: IXIT FLChI

IFI [TCROL .NE.O) WP.ITE $(6,1110)$ TCIJ) $) \times 3, \times 4$

1110 FORMAT $(1 H+, 61 X$, SHCBOLEN TO,F7.1,5H DEG, A4,A3)

50 CONTINLE

TYPEF $=$ TYPFFP

IF(KPOLY.FO.O) TYPEF = TYPEFI

WRITE $(t, 1120)$ ETAETA, TYPEF

1120 FORMATI 2 OHOOIITPUT POWER EQUALS,F7.4,15H OF SHAFT POWER, 2OX, 31HTUFR IOMACHINERY EFFICIENCIES ARE, A5, GHTF OPICI

IFIKOIIT.FQ.O) WRITE $(6,2000) \times 7, \times 7, \times 8$

2000 FORMAT ( $8 H 1$ PZESS., 6X, 3HNET, $8 X, 3$ HNET, $8 X, 4 \mathrm{HFUEI}, 7 X, 5 \mathrm{HCYCLE}, 6 X, 4 \mathrm{HFUEL}$

$1,18 X, 18 H$ P NWER VAL UES REFER $17 \mathrm{H}$ RATIO,6X,5HPTWER,6X,5HPOWER, 5X, $8 H C$

$20 N S U M P$. 6X, 3HEFF, 6X, 5HPOWEF, $18 X, 7 H T O$ DNE, A2, BH PEF SEC/14X,2HKW, 9

$3 X, 2 H H P, 7 X, A 2,4 H / H R /, A 2,17 X, 2 H K W, 19 X, 17 H O F$ INLET AIR FLOWI

IF(III.EQ.2) GN TO 16

$T S O=T S C * 1.8$

17 nก $36 \quad I=1$, NSHAFT

I I $=$ NCONP(I)

OO $21 L=1,11$

$21 \operatorname{TINT}(L, I)=\operatorname{TINT}(L, I) * 1.8$

I $J=N T U R R$ (I)

DO $37 \mathrm{~L}=1, \mathrm{IJ}$

$37 T T I(L, I)=T T I(L, I) * 1.8$

36 C.ONTINLE

$H V F=H V F / 1055.87 * .45359237$

$T R=T R * 1.8$

$T F=T F * 1.8$

$A F=A F / 1055.87 * .45359237 / 1.8$

$B F=A F / 1055.87 * .45359237 / 1.8 / 1.8$

$C F=C F / 1055.87 * .45359237 / 1.8 / 1.8 / 1.8$

IF(ITF.GE:10) TFIN= TFIN*I.8

IF( ITCOOL.EQ. 1$) \quad$ TCOOL $=$ TCOOL* 1.8

c

C

INLET CONDITIONS

16 TTO $=T S C$

PTO $=P$ SO

$W O=1 .+k$

C

C

C

INL ET

$5 T T I=T T C$

P T $1=P T C * R 10$

$W 1=W 0$

$R C=R C M I N$

6 CONTINLE

$D L H C=C . O$

C

CALL FUEL

C

START INTERCOOLFR-COMPRESSTR LOOP

DO $150 I=1, N S H A F T$

$I S=N S+A F T+I-I$

RCSHFT(IS) $=R C * R C$ SHSP (IS)

DEL. HSH I IS $)=0.0$

$I F(I-1) \quad 2,2,3$ 


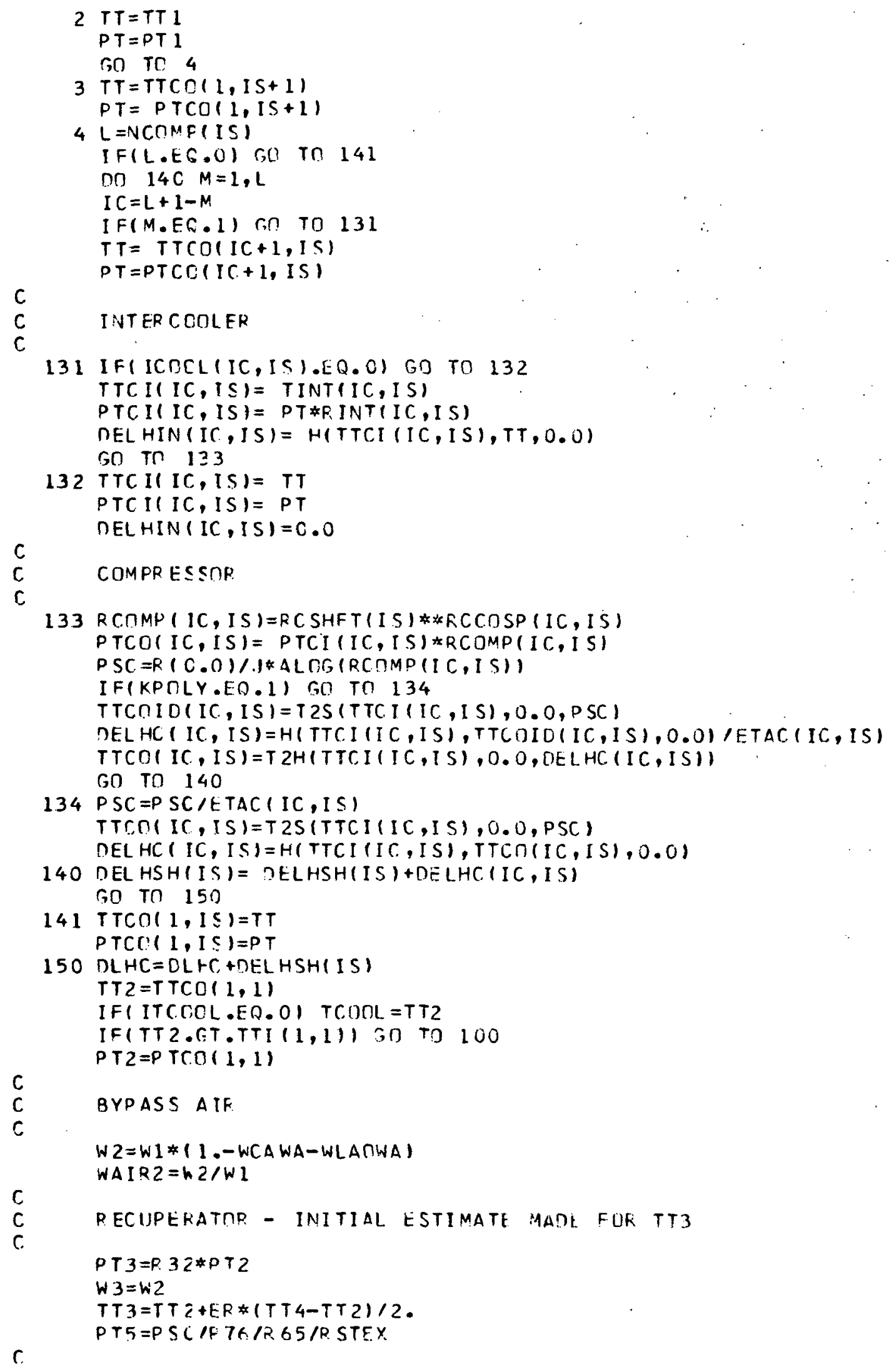




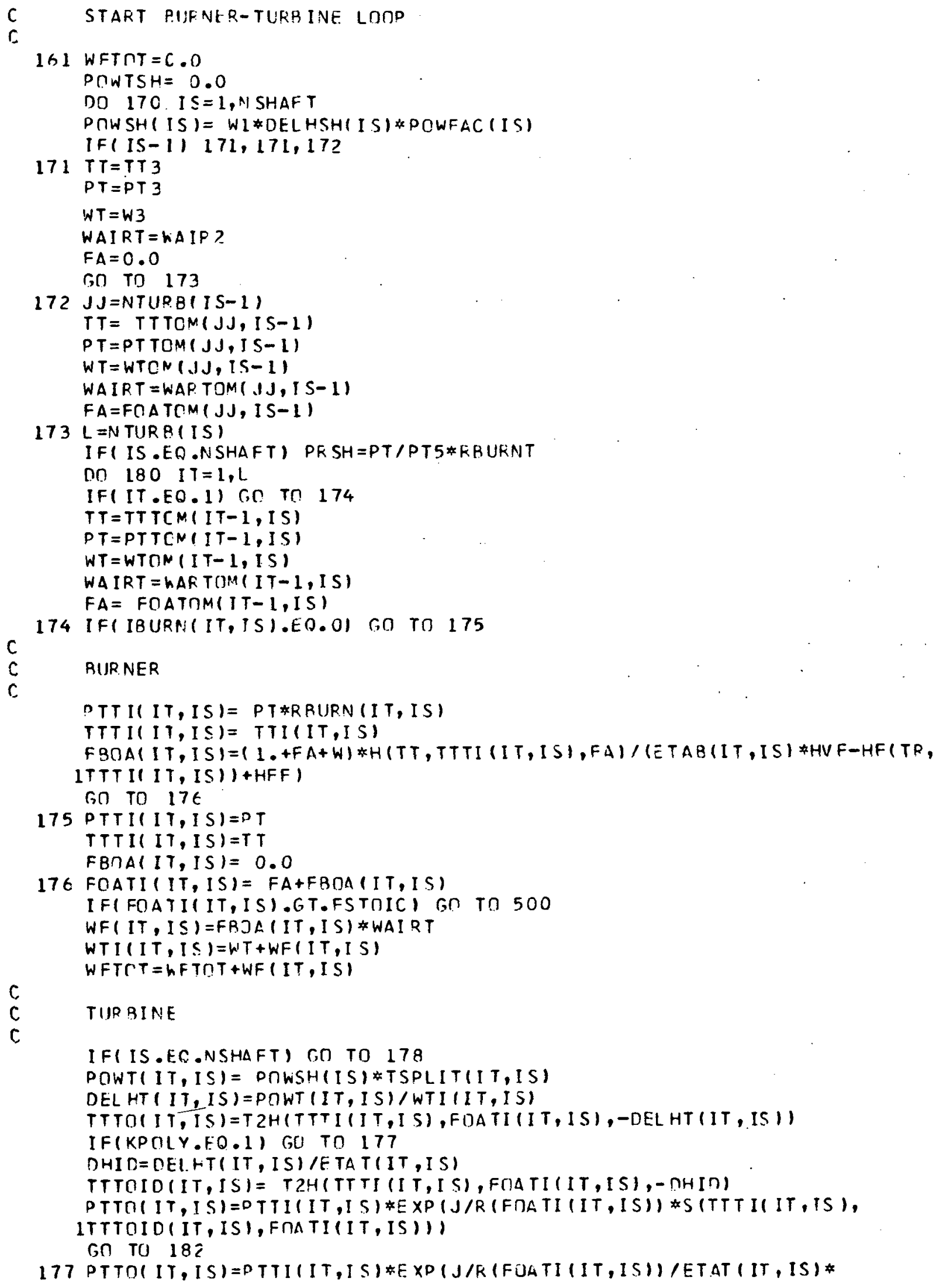

$173 \mathrm{~L}=\mathrm{N}$ TUR B (IS)

IFI IS . ER.NSHAFT) PRSH =PT/PT5 *RURNT

DO $180 \quad$ IT $T=1, L$

IF(IT.EO.1) GO TO 174

$T T=T T T C M(I T-1, I S)$

PT $=$ PT TCN (IT-1,ISI

$W T=W T O N(I T-1, I S)$

WAIRT = hARTOM(IT-1, IS)

$F A=F O A T \cap M(I T-1, I S)$

C

174 IFI IBURN(IT,IS).EO.OI GO TO 175

C RIJRNER

$c$

PTTI(IT, IS)= PT*RRURN (IT, IS)

TTTI(IT, IS) = TTI $(I T, I S)$

FBOA IT, IS $=(1,+F A+W) * H(T T, T T T I(I T, I S), F A) /(E T A B(I T, I S)$ \#HVF-HF(TR, ITTT I( IT, ISI)+HFF)

go to 176

175 PTTI(IT, IS) $=$ PT

TTTI IT, IS ) =T T

FBกA $(I T, I S)=0.0$

176 FOATI $(I T, I S)=F A+F B O A(I T, I S)$

IF(FOATI(IT, IS).GT.FSTMICI GO TO 500

WF $(I T, I S)=F R J A(I T, I S)$ *WAIRT

WTI (IT, I $S)=W T+W F(I T, I S)$

$\mathrm{C}$ WFTCT $=$ hFTOT +WF (IT, IS)

C TIIR RINE

C

IF( IS.EC.NSHAFT) GO TO 178

POWT(IT, IS) = POWSH(IS) *TSPLIT(IT, IS)

DEL HT $(I T, I S)=P(W T(I T, I S) / W T I(I T, I S)$

TTTOI IT,IS)=T2H(TTTI IT, I S), FDATI IIT, ISI, -DELHT (IT, IS I)

IF(KPOLY.EO.1) GU TO 177

DHID=DEL.HTI IT, IS) /ETAT (IT, IS)

TTTOID IT,IS) = T2H(TTTI I T,IS), FOATI (IT,IS), - NHIN)

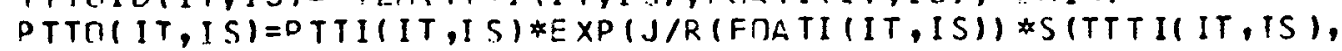

ITTTOID(IT, ISI, FOATI(IT, IS))

Gก TO 182

177 PTTOI IT, IS)=PTTI(IT, IS) \#EXP(J/R (FUATI (IT, IS ) /ETAT IT, IS)* 
ISITTTIIT, IS), TTTOIT, ISI,FOATIIT,ISI)

GO TO 182

178 PRT IIT, IS ) = PRSH* TSPLIT(IT,IS)

$P S T=F$ ( FCATIIIT, IS) IJ*ALOG(I, /PRT(IT,IS)

PTTD IT, IS $=$ PTTIIIT,ISI/DRT IIT,IS)

IF(K.POLY.EO. I) GO TO 179

TTTOIח(IT, IS) = T2S(TTTI(IT, ISI, FOATI IT, IS),PST)

DEL HT (IT, IS) =L TAT (IT, I S) *H (TTTOIU(I T, I S), TT TI (IT, IS), FOATI (IT, IS)

TTTOI IT, IS ) =T2HITTTIIIT,IS), FOATIIIT, ISI, -DELHT (IT, IS I)

STO TO 181

179 PST $=$ DST*ETAT $(I T, I S)$

TTTO(IT, IS)=T 2S(TTTI I T, I S), FUATI I T, IS),PST)

DELHTI IT, IS)=H(TTTM(IT, IS),TTTI IT, IS), FOATI(IT, IS) )

181 POWT $(I T, I S)=W T I I I T, I S) * D E L H T(I T, I S)$

POWTSH=POWTSH+POWT $(I T, I S)$

C

C

C

$182 \operatorname{PTTOM}(11, I S)=\operatorname{PTTH}(I T, I S)$

IF(DTTCIIT,ISI.LT.PT5*.9999) GO TO 200

WTCM(IT,IS) = WTIIIT,IS)+WL*WCAOWA(IT, IS)

WARTOM IIT, IS ) = WAIRT+WCANWA $(I T, I S)$

FOATOM(IT, IS) = FOATI (IT,IS) *WAIFT/WARTOMIIT,IS)

IF( WCAOWA (IT, IS).EO.0.0) GO TO 183

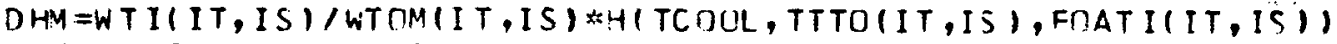

TTTOM (IT, IS) = T2HITCONL,FJATOM(IT, IS), DHM)

GO TJ $18 \mathrm{C}$

183 TTTOM (IT, IS $=\operatorname{TTTC}(I T, I S)$

180 CONTINUE.

17 C CONTINUE

IF(POWTSF .LT.WI\$DELHSHINSHAFT)) GO TR 400

TTS $=$ TTTOM( JJJ, NSHAFT)

PTS = PTTOM(JJJ, NSHAFT)

W5 $=$ WTCN ( JJJ, NSHAFT)

FOA $5=$ FOATOMM(J JJ, IVSHAFT)

C

WAIF $5=W A R T \cap M(J J J, N S H Q F T)$

C RECOVERY IIFFUSFR

C

$T T G=T T S$

$P T G=P T E * R \in 5$

FOA $6=F O A 5$

$W 6=W 5$

C

WAIR6 = WAIR 5

C RECUPERATIP

C

IFIER. .EQ.0.0) GO TO 2\%

IF(TTG.LT.TT2) GO Tח 300

DHF $=E R * H(T T 2, T T 6,0.0)$

TT 3PF E $=$ TT 3

$T T 3=T 2+(T T 2,0,0, D H R)$

IF(ABS(TT3-TT 3PRE). .T. TTOL) GO TO 161

$T T 7=T 2 H(T T G, F \cap A 6,-W 2 / W G$ * IHR )

GO TO 25

24 TTP $=T T E$

$25 W 7=W 5$

FOA $7=F \cap A G$

WAIRT $=$ LAIP 6 


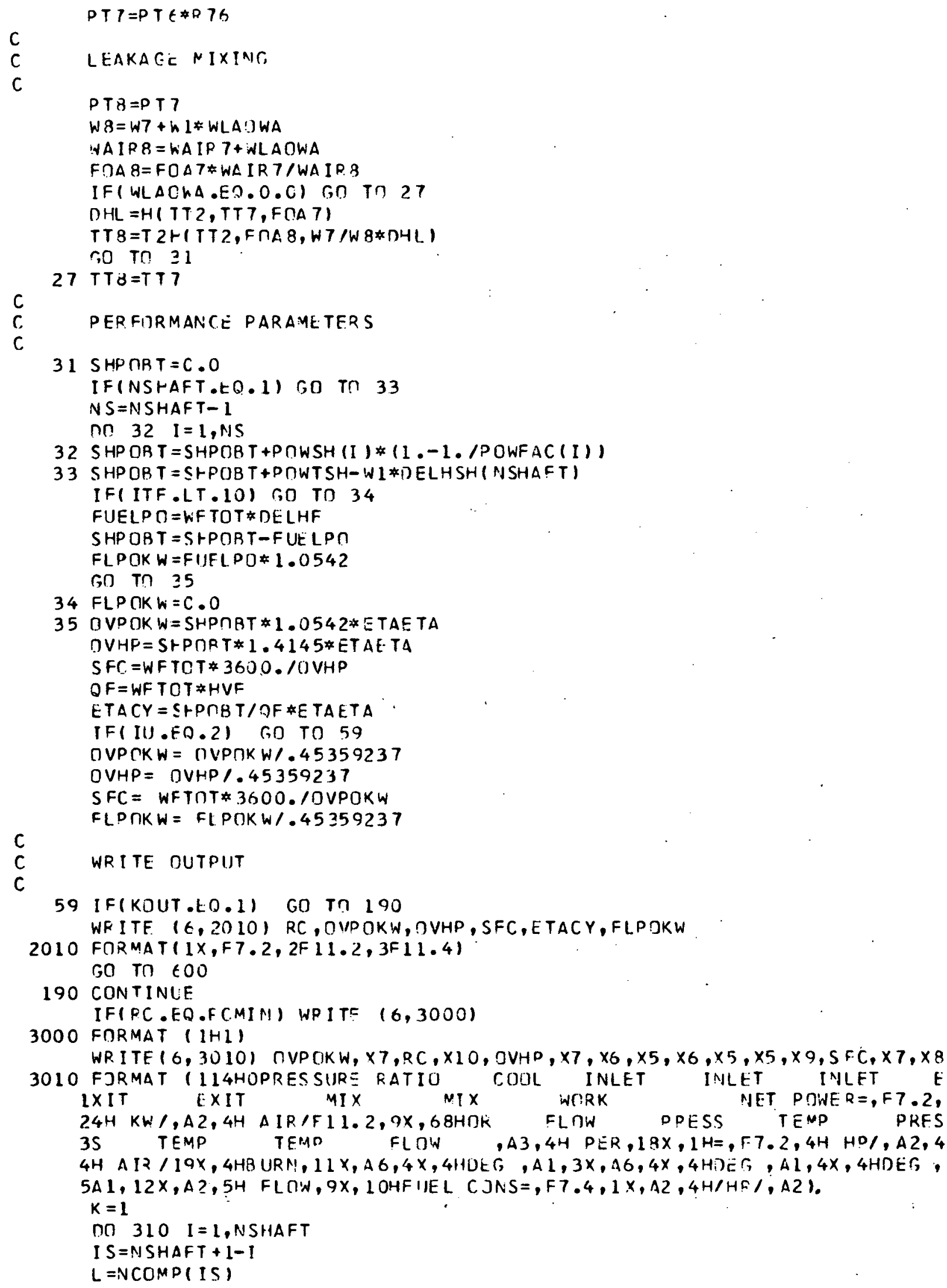


I FIL.EF .OI R,I TO 310

nח $308 \quad N=1,1$

$I C=L+I-N$

IF(IU.EC.2) GO TO 191

TTCII IC, IS $=$ TTR.IIIC,IS)/L.8

TTCO(IC, IS) = TTCUIIC, IS)/1. ?

DELHC (IC, IS $=$ OFLHC IIC,IS) $* 1055.87 / 453.59237$

$191 Y N=$ OFF

IF( ICOOLIIC, IS ).NE.OOI YN $=I$ IN

WRITE $(\epsilon, 3 \cup 20)$ IS, IC, VN,Wl, PTCI (IC, IS), TTCI IC, IS), PTCOIIC, IS),

ITTC II IC, IS), )EI.HC (IC, IS)

3020 FOFMAT(6H SHCFT, I 2, 7H - CIJMP, I $2, A 5, F 9.4,4 F 9.1,21 \times, F 7.21$

I F(K.EC.1) WR ITE $(6,3) 21)$ VTACY

3021 FORMATI IH+, 103X,1OHCYCLE EFF =,F7.4)

IF(K.EQ.2) NRI TE $(6,3022)$ FLPOKW, $X 7$

3022 FOPMAT ( IH+, $103 \mathrm{X}, 1$ OHFUEL POUK $=, F 7.4,4 \mathrm{H} \mathrm{KW} /, \mathrm{A} 2,4 \mathrm{H}$ AIR)

$K=K+1$

308 CNNTINLE

310 CONTINLE

IF(IU.EO.2) GC, TO 311

$T T 2=T T 2 / 1.8$

$T T 3=T T 2 / 1.8$

31 I WRITE ( E, 3030) W2, PT2, TT2,PT3,TT3

3030 FDRMATI $12 \mathrm{H}$ RFCUPERATIR, 10X,F9.4,4F9.1)

I F(K.EG.2) WF. ITF $(6,3022) \quad F L D O K W, X 7$

DO 320 I $S=1$, N SHAFT

$L=N T U R P$ (IS)

nח $320 \quad I T=1, L$

IF(IU.EO.2) RO TO 312

TTTI $(I T, I S)=T T T I(I T, I S) / 1 . B$

TTTO(IT, IS $=$ TTTO (IT,IS)/1.

$\operatorname{TTTOM}(I T, I S)=\operatorname{TTTOM}(I T, I S) / 1.8$

DEL.HT $(I T, I S)=$ DELHT (IT, IS $) * 1055.87 / 453.59237$

$312 Y N=O F F$

I F(IBURN(IT, IS) .NE.G) YN=TN

320 WF ITE $(\epsilon, 3040)$ IS, IT, YN,WTI (IT, I S), PTTI (IT, IS), TTTI (IT, IS), PTTO(IT

1, IS), TTTO(IT, IS), TTTOM (IT, I S), WTOM(IT, IS), DEL.HT (IT, IS)

3040 FORMATIEH SHAFT, I 2,7H - TURB, I 2, A5, F9.4,5F9.1,F9.4,F10.21

I F(IU.EQ.2) GO TO 313

$T T 6=T T 6 / 1.8$

$T T 7=T T 7 / 1.8$

$T T 8=T T \varepsilon / 1.8$

313 WRITE $(\epsilon, 3050)$ WE, PT6,TT6,PT7,TT7,TT8, W8

$305 C$ FORMAT(12H RECUPE RATOR, $10 \times, F G .4,5 F 9.1, F 9.4111$

S,O TO $E O C$

100 IF(IU.EN.1) TT2=TT2/1.3

IF (IU.EO.1) TTI $(1,1)=\operatorname{TTI}(1,1) / 1.8$

WFITE $(t, 5000)$ RC, TT2, TTI $(1,1)$

5000 FORMAT $(1 X, F 7.2,4 X$,

1

22HC CMPRESSUR EXIT TEMP $(, F 6.1,35 H)$ TREATER THAN TURRIN

IE INLET TEMP $(, F 6.1,1 H)$ )

IF( IU.EQ. 1) TTI $(1,1)=\operatorname{TTI}(1,1) * 1.8$

GO Tח 1

200 WRITE $(6,6000)$ RC,PT5, IT,IS,PTTO(IT,IS)

6000 FIRMATI IX,FT . 2, 4X,30HTURBIIJE-SYSTEM EXIT PRESSURF: $(, F 6.2,42 H)$ GREA

LTER THAN TUR 3 INE EXIT PRESSURE PTTC $(, 11,1 \mathrm{H}, 111,2 \mathrm{H})=, F G .2)$

SO TO $E$ TOO

300 IF(IU.EQ.1) TT6=TTG/1.3

IF( IU.EQ.1) TT2=TT2/1.8 
WPTTE $(6,7000) P C, T T S, T T 2$

7000 FחRMATI $1 X, F 7.2,4 X$,

1 32HPEC UPEPATMR HIIT SAS INLET TEMP $(, 96.1,35 H)$ CCIDER TH

IAN COLC GAS INLET TEMP $1, F 6,1,1 H) 1$

Gח TO 1

400 WRITE (E, 8000$)$ FC, NSHAFT

8000 FJRMAT $(1 X, F 7.2,4 X, 49 H T$ TIRBINE POWLR LESS THAN COMOFFSSUP PIIHER ON $S$

1HAFT, I ¿ I

GO TO $E C O$

500 WRITE $(6,9000)$ RC, IT, IS

9000 FחRMAT ( $1 X, F 7.2,4 X, 24 H O X Y G F N$ USE UP IN BUPNER, $12,9 H$ ON SHAFT, I 2$)$

GOO CONTINUE

$R C=R C+R C \cap E L$

I $F(R C-T E S T) \quad 6,1,1$

ENก

Subroutine FUEL

Subroutine FUEL performs the computations involving the fuel thermodynamic properties and the fuel compression.

Program variables. - Certain of the variables transfer between main program MULTI and subroutine FUEL by means of labeled common block/CFUEL/. These variables, which were defined in the MULTI variable list, are AF, BF, CF, DELHF, ETACF, HFF, ITF, MWF, PRFIN, RC, TF, TFIN, and TR. The remaining variables in subroutine FUEL are defined as follows:

CP arithmetic statement function for heat capacity of fuel, eq. (C1)

DFSCF derivative of FSCF with respect to TF

FSCF difference between right- and left-hand șides of eq. (C8)

$\mathrm{H}$ arithmetic statement function for fuel enthalpy difference, eq. (C2)

NCF number of fuel compressors with intervening intercoolers

PRC pressure ratio across one fuel compressor

PSCF value of function $\Phi_{f}$ in eq. (C8)

S arithmetic statement function defined by eq. (C3)

T temperature

TF1 previous value of $T F$

Program listing. - The FORTRAN listing for subroutine FUEL is as follows: 


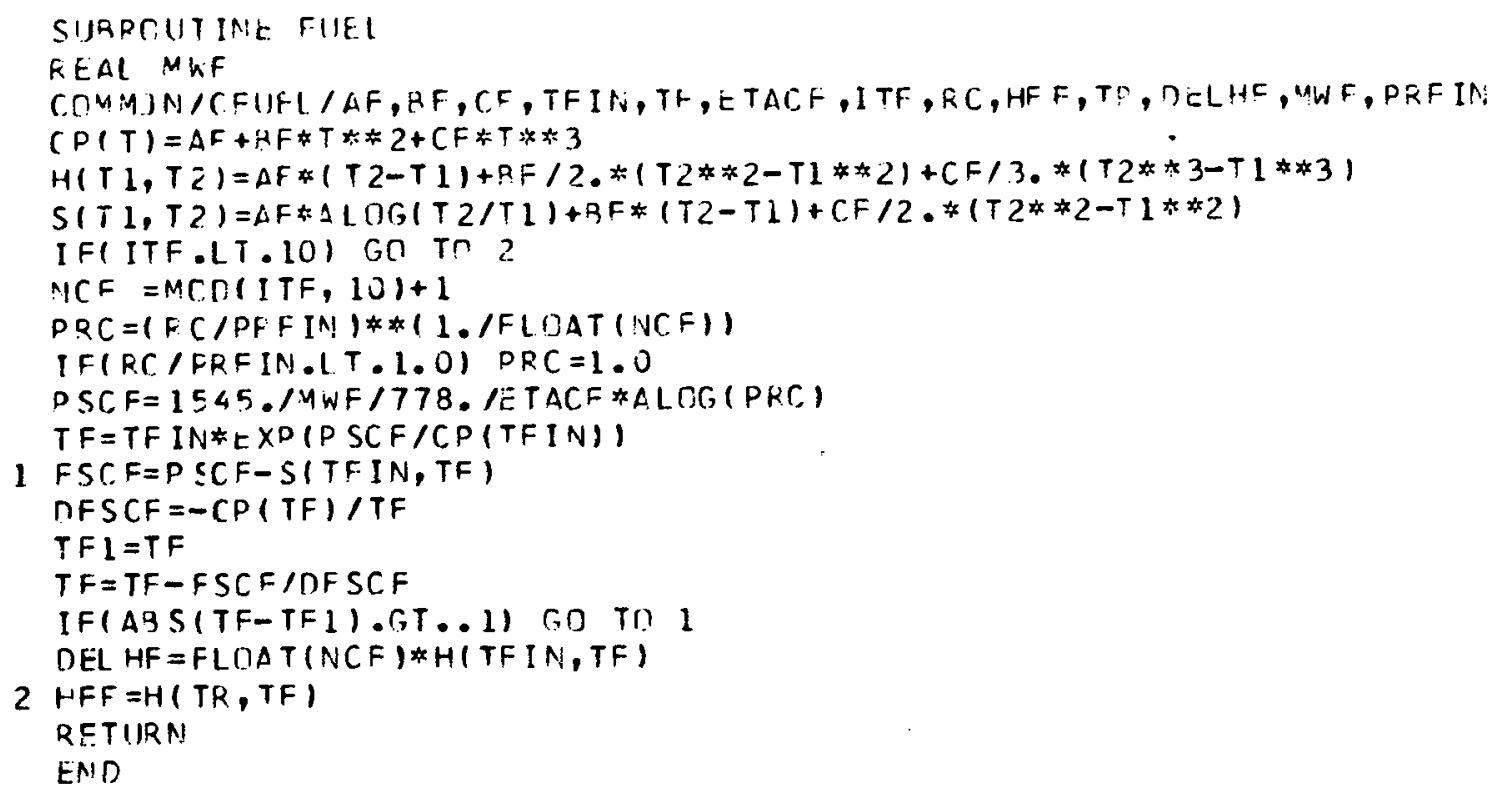

Combustion-Gas Thermodynamic-Property Subprograms

All calculations directly involving the combustion-gas thermodynamic properties are performed by subroutine THERMO. In order to use the values computed in THERMO directly in arithmetic statements of the calling program, there are six function subprograms used in conjunction with THERMO. Each function subprogram calls on THERMO to do one particular computation, and the results of this computation is then set equal to the function. The six types of computation done by THERMO and the associated functions, with arguments, are as follows:

Function Computation

$\mathrm{CP}(\mathrm{T}, \mathrm{F}) \quad$ heat capacity $\mathrm{c}_{\mathrm{p}}$ from eq. (B5)

$\mathrm{H}(\mathrm{T} 1, \mathrm{~T} 2, \mathrm{~F}) \quad$ enthalpy difference $\Delta \mathrm{h}$ from eq. (B7)

$\mathrm{T} 2 \mathrm{H}(\mathrm{T} 1, \mathrm{~F}, \mathrm{X}) \quad$ final temperature $\mathrm{T}_{2}$ by iteration from eq. (B7)

$\mathrm{S}(\mathrm{T} 1, \mathrm{~T} 2, \mathrm{~F}) \quad$ entropy function $\Delta \varphi$ from eq. (B12)

T2S $(T 1, F, X) \quad$ final temperature $T_{2}$ by iteration from eq. (B12)

$\mathrm{HF}(\mathrm{T} 1, \mathrm{~T} 2) \quad$ function $\mathrm{I}\left(\mathrm{T}_{1}, \mathrm{~T}_{2}\right)$ from eq. (B10)

The function arguments, which are known values for each computation, are defined as follows: 
F fuel-air ratio

T temperature

T1 initial temperature

T2 final temperature

$\mathrm{X}$ function value of $\Delta \mathrm{h}$ or $\Delta \varphi$

The call on subroutine THERMO is CALL THERMO(TIN, TOUT, FOA, FUNC, IND) where the arguments are defined as follows:

FOA fuel-air ratio

FUNC function value

IND computation-type indicator:

$$
\begin{aligned}
& 1-c_{p} \\
& 2-\Delta h \\
& 3-T_{2} \text { from } \Delta h \\
& 4-\Delta \varphi \\
& 5-T_{2} \text { from } \Delta \varphi \\
& 6-I\left(T_{1}, T_{2}\right)
\end{aligned}
$$

TIN initial temperature

TOUT final temperature

This set of subprograms can be used with any program requiring combustion-gas thermodynamic properties.

Program variables. - The only variables used in the function subprograms are the function and its arguments, all of which have been defined. Certain of the variables used in subroutine THERMO are transmitted from main program MULTI through unlabeled common. These are HOC, TTOL, and W, which were defined in the MULTI variable list. The remaining variables in THERMO, with the exception of the functions and arguments defined previously, are defined as follows:

A constant $A_{\text {air }}$ in eq. (B5)

ACO2 constant $\mathrm{A}_{\mathrm{CO}_{2}}$ in eq. (B5)

AH2O constant $\mathrm{A}_{\mathrm{H}_{2} \mathrm{O}}$ in eq. (B5)

AO2 constant $\mathrm{A}_{2}$ in eq. (B5) 
A1 constant $\mathrm{K}_{1}$ in eq. (B5)

A.2 constant $\mathrm{K}_{2}$ in eq. (B5)

A3 constant $K_{3}$ in eq. (B5)

$B$ constant $B_{\text {air }}$ in eq. (B5)

$\mathrm{BCO} 2$ constant $\mathrm{B}_{\mathrm{CO}_{2}}$ in eq. (B5)

$\mathrm{BH} 2 \mathrm{O}$ constant $\mathrm{B}_{\mathrm{H}_{2} \mathrm{O}}$ in eq. (B5).

$\mathrm{BO} 2$ constant $\mathrm{B}_{\mathrm{O}_{2}}$ in eq. (B5)

$C$ constant $\mathrm{C}_{\text {air }}$ in eq. (B5)

$\mathrm{CCO} 2$ constant $\mathrm{C}_{\mathrm{CO}_{2}}$ in eq. (B5)

CH2O constant $\mathrm{C}_{\mathrm{H}_{2} \mathrm{O}}$ in eq. (B5)

$\mathrm{CO} 2$ constant $\mathrm{C}_{\mathrm{O}_{2}}$ in eq. (B5)

$D$ constant $D_{\text {air }}$ in eq. (B5)

$\mathrm{DCO} 2$ constant $\mathrm{D}_{\mathrm{CO}_{2}}$ in eq. (B5)

DFCN derivative of function FCN with respect to TOUT

DH2O constant $\mathrm{D}_{\mathrm{H}_{2} \mathrm{O}}$ in eq. (B5)

$\mathrm{DO2}$ constant $\mathrm{D}_{\mathrm{O}_{2}}$ in eq. (B5)

$\mathrm{E}$ constant $\mathrm{E}_{\text {air }}$ in eq. (B5)

$\mathrm{ECO} 2$ constant. $\mathrm{E}_{\mathrm{CO}_{2}}$. in eq. (B5)

$\mathrm{EH} 2 \mathrm{O}$ constant $\mathrm{E}_{\mathrm{H}_{2} \mathrm{O}}$ in eq. (B5)

$\mathrm{EO} 2$ constant $\mathrm{E}_{\mathrm{O}_{2}}$ in eq. (B5)

FCN difference function for iterative solution for TOUT

TPRE previous value of TOUT

Program listing. - The FORTRAN listings for function subprograms $\mathrm{CP}, \mathrm{H}, \mathrm{T} 2 \mathrm{H}$, $\mathrm{S}, \mathrm{T} 2 \mathrm{~S}$, and HF and for subroutine THERMO are as follows:

FUNCT ICN CPIT, F)

CALL THERMO $(T, 1,, F, X, 1\}$

$C P=X$

RETURN

END 
FUIJCT ICN $H(T 1, T 2, F)$

CALL THERMO $(T 1, T 2, F, X, 2)$

$\mathrm{H}=\mathrm{X}$

P. STUR.N

END

FUNCT ION T2H(T $1, F, X)$

CALL THERMO $(T 1, T 2, F, X, 3)$

$T 2 H=T 2$

RETURN

END

FUNCT ION $S(T 1, T 2, F)$

CALL THERMO $(T 1, T 2, F, X, 4)$

$S=X$

RETURN

END

FIJNCT ION T2S(T $1, F, X)$

CALL THEPMO $(T 1, T 2, F, X, 5)$

$T 2 S=T 2$

RETURN

END

FUNCTICN HF(T 1,T2)

CALL THERMD $(T 1, T 2,1,, X, 6)$

$H F=X$

RETIRN

END

C

SIRPLUTINE: THERMU (TIN,TOUT: FOA, FUNC, IND)

C THERMOOYNAMIC PROPERTY SUBPDUTINE

C

C IND

C

c

1

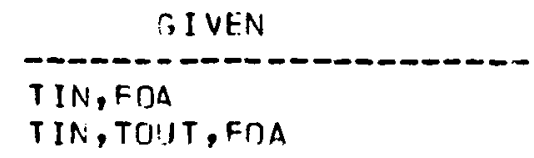

CALCULATED

CP(TIN,FOA)

H(TOUT, TIN, FDA) 


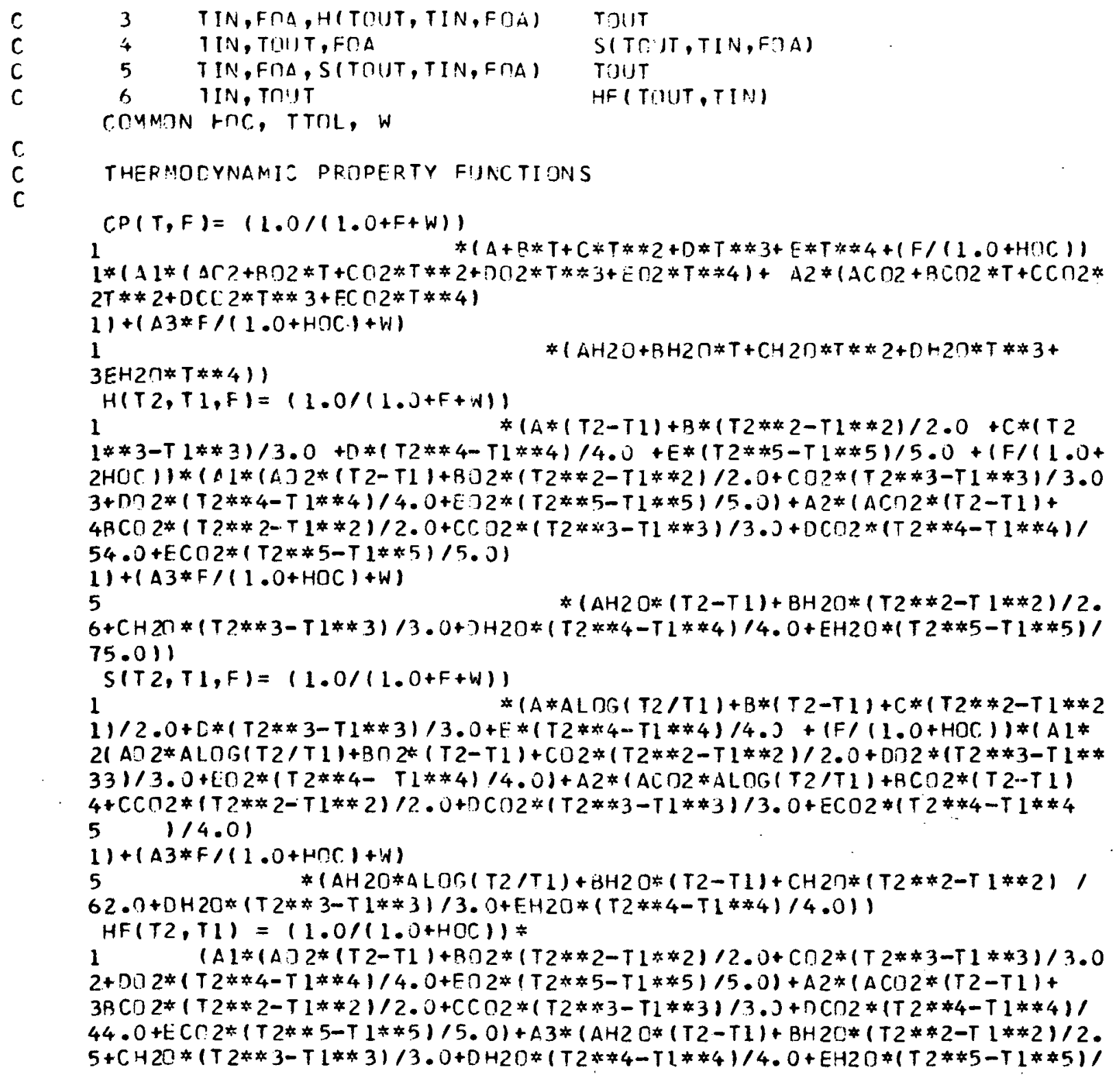

THERM - EFN SDIJRCE STATEMENT - IFNISI

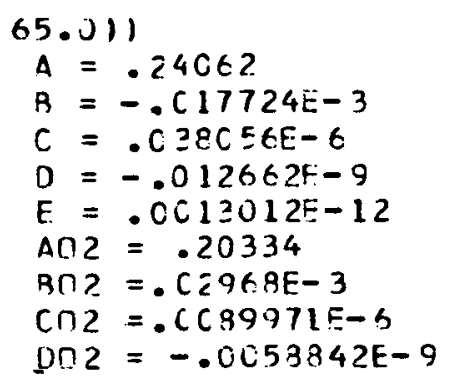




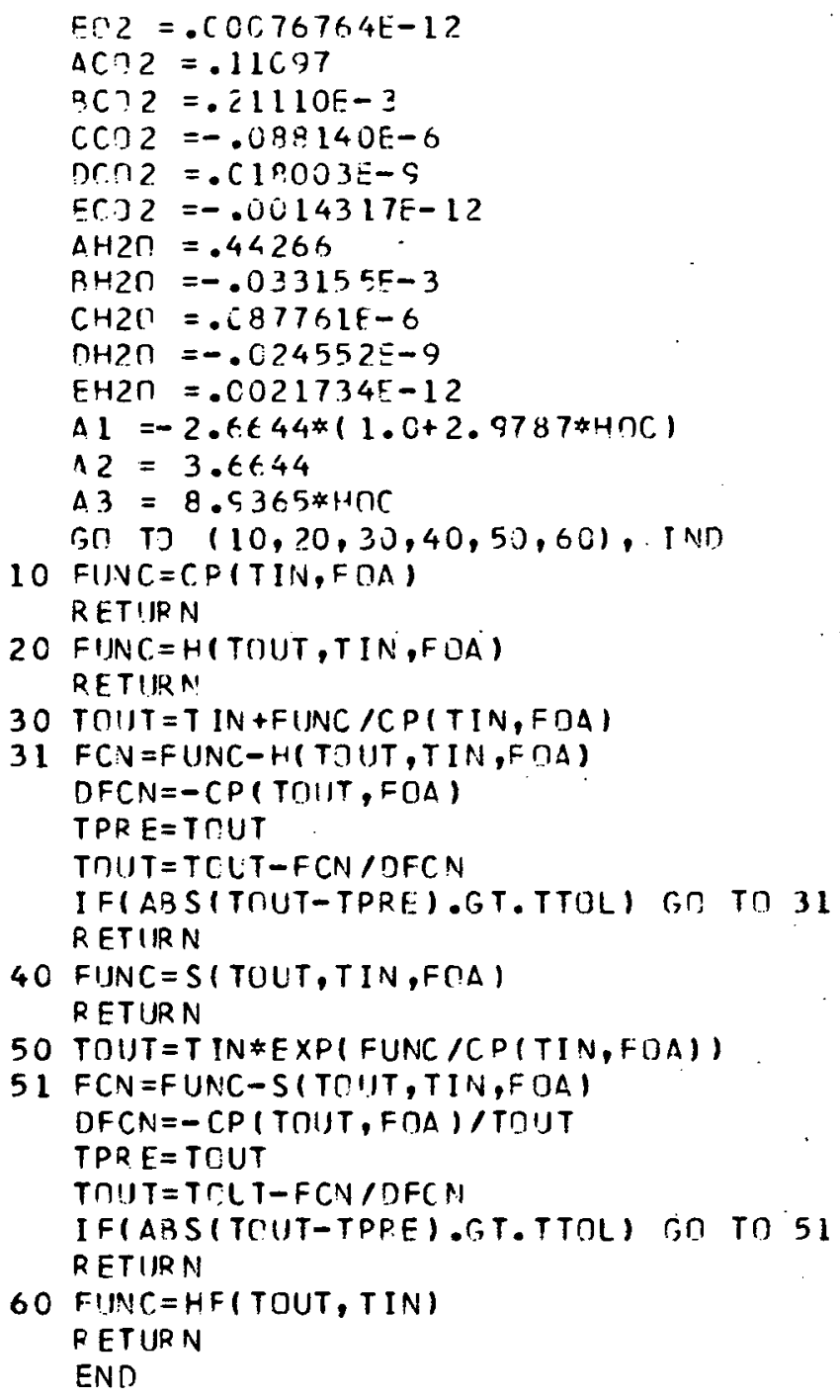

Lewis Research Center,

National Aeronautics and Space Administration,

Cleveland, Ohio, October 3, 1974, 501-24. 


\section{APPENDIX A}

\section{SYMBOLS}

A

B

C

$c_{p}$

D

E

f

$\mathrm{H}$

$\mathrm{H}_{\mathrm{f}}$

$\Delta \mathrm{h}$

$\Delta \mathrm{h}_{\mathrm{cb}}$

I

J

$\mathrm{K}_{\mathrm{P}}$

$\mathrm{K}_{1}, \mathrm{~K}_{2}, \mathrm{~K}_{3}$

M

m

${ }^{n_{C, f}}$

$\mathrm{n}_{\mathrm{sh}}$

$\mathbf{P}$

$\mathrm{p}$

$\mathbf{R}$

$\mathbf{r}$

SFC

$\mathrm{T}$

w constant in heat capacity equation, eq. (B4), $\mathrm{J} /(\mathrm{kg})(\mathrm{K})\left(\mathrm{Btu} /(\mathrm{lb})\left({ }^{\mathrm{O}} \mathrm{R}\right)\right)$

constant in heat capacity equation, eq. (B4), $\mathrm{J} /(\mathrm{kg})\left(\mathrm{K}^{2}\right)\left(\mathrm{Btu} /(\mathrm{lb})\left({ }^{\mathrm{O}} \mathrm{R}^{2}\right)\right)$

constant in heat capacity equation, eq. (B4), $\mathrm{J} /(\mathrm{kg})\left(\mathrm{K}^{3}\right)\left(\mathrm{Btu} /(\mathrm{lb})\left({ }^{\mathrm{O}} \mathrm{R}^{3}\right)\right)$ heat capacity, $\mathrm{J} /(\mathrm{kg})(\mathrm{K})\left(\mathrm{Btu} /(\mathrm{lb})\left({ }^{\mathrm{O}} \mathrm{R}\right)\right)$

constant in heat capacity equation, eq. (B4), J/(kg) $\left(K^{4}\right)\left(B t u /(1 b)\left({ }^{\circ} R^{4}\right)\right)$

constant in heat capacity equation, eq. (B4), $\mathrm{J} /(\mathrm{kg})\left(\mathrm{K}^{5}\right)\left(\mathrm{Btu} /(\mathrm{lb})\left({ }^{\mathrm{O}} \mathrm{R}^{5}\right)\right)$

fuel-air ratio

enthalpy function $\Delta \mathrm{h}$ as defined by eq. (B7), J/kg (Btu/lb)

enthalpy function $\Delta \mathrm{h}_{\mathrm{f}}$ as defined by eq. (C4), J/kg (Btu/lb)

enthalpy difference or specific work, $\mathrm{J} / \mathrm{kg}$ (Btu/lb)

heat of combustion of fuel, $\mathrm{J} / \mathrm{kg}(\mathrm{Btu} / \mathrm{lb})$

enthalpy correction function as defined by eq. (B10), J/kg (Btu/lb)

dimensional constant, 1 (778 ft-lb/Btu)

ratio of turbine power to compressor power

constants in heat capacity equation, eq. (B5)

molecular weight

ambient air absolute humidity

number of fuel compressors with intervening intercoolers

number of shafts

power, kW (Btu/sec)

absolute pressure, $\mathrm{N} / \mathrm{cm}^{2}$ (psia)

gas constant, $\left.\mathrm{J} /(\mathrm{kg})(\mathrm{K})(\mathrm{ft})(\mathrm{lbf}) /(\mathrm{lbm})\left({ }^{\mathrm{O}} \mathrm{R}\right)\right)$

ratio of component exit to inlet total pressure

specific fuel consumption, $\mathrm{kg} /(\mathrm{hr})(\mathrm{kW})(\mathrm{lb} /(\mathrm{hr})(\mathrm{hp}))$

absolute temperature, $\mathrm{K}\left({ }^{\circ} \mathrm{R}\right)$

mass flow rate per pound of inlet air, $\mathrm{kg} / \mathrm{sec}(\mathrm{lb} / \mathrm{sec})$ 
$x \quad$ atom ratio of hydrogen to carbon in fuel

$y \quad$ mass ratio of hydrogen to carbon in fuel

$\eta \quad$ efficiency or effectiveness

$\Phi \quad$ entropy function $\Delta \varphi$ as defined by eq. $(\mathrm{B} 12), \mathrm{J} /(\mathrm{kg})(\mathrm{K})\left(\mathrm{Btu} /(\mathrm{lb})\left({ }^{\mathrm{O}} \mathrm{R}\right)\right)$

$\Phi_{\mathrm{f}} \quad$ entropy function $\Delta \varphi_{\mathrm{f}}$ as defined by eq. $(\mathrm{C} 8), \mathrm{J} /(\mathrm{kg})(\mathrm{K})\left(\mathrm{Btu} /(\mathrm{lb})\left({ }^{\mathrm{O}} \mathrm{R}\right)\right)$

$\Delta \varphi \quad$ constant-pressure entropy change, $\mathrm{J} /(\mathrm{kg})(\mathrm{K})\left(\mathrm{Bti} ;(\mathrm{ib})\left({ }^{\mathrm{O}} \mathrm{R}\right)\right)$

Subscripts:

air air

B burner

C compressor

$\mathrm{CO}_{2}$ carbon dioxide

c turbine coolant

cold cold side

cv conversion

cy cycle

D diffuser

est estimated

ex exit

f fuel

$\mathrm{H}_{2} \mathrm{O}$ water vapor

hot hot side

I inlet component

INT intercooler

id ideal

in inlet

j shaft $\mathbf{j}$

$l$ recuperator leakage

m mixed

net net

$\mathrm{O}_{2} \quad$ oxygen 


$\begin{array}{ll}\text { o } & \text { overall } \\ \mathrm{p} & \text { polytropic } \\ \mathrm{R} & \text { recuperator } \\ \mathrm{r} & \text { reference } \\ \text { sh } & \text { shaft } \\ \mathrm{T} & \text { turbine } \\ \text { tot } & \text { total } \\ 0 & \text { ambient condition, see fig. } 5 \\ 1 & \text { initial; station between inlet and compressor, see fig. } 5 \\ 2 & \text { final; station between compressor and recuperator, see fig. } 5 \\ 3 & \text { station between recuperator and primary burner, see fig. } 5 \\ 4 & \text { station between primary burner and turbine, see fig. } 5 \\ 5 & \text { station between turbine and diffuser, see fig. } 5 \\ 6 & \text { station between diffuser and recuperator, see fig. } 5 \\ 7 & \text { station at recuperator hot-side through-flow exit, see fig. } 5 \\ 8 & \text { station at recuperator hot-side exit after leakage mixing, see fig. } 5 \\ \text { Superscipt: } \\ \text { absolute total state }\end{array}$




\section{APPENDIX B}

\section{DERIVATION OF COMBUSTION-GAS PROPERTY EQUATIONS}

\section{Reaction Stoichiometry}

The fuel used has the composition $\mathrm{CH}_{X}$, and the general combustion equation with associated formula weights is

$$
\overbrace{12.010+1.008 \times}^{\mathrm{CH}_{\mathrm{x}}}+\overbrace{32.000\left(1+\frac{\mathrm{x}}{4}\right)}^{\left(1+\frac{\mathrm{x}}{4}\right) \mathrm{O}_{2}} \overbrace{44.010}^{\mathrm{CO}_{2}+\left(\frac{\mathrm{x}}{2} \mathrm{H}_{2} \mathrm{O}\right)} \overbrace{18.016\left(\frac{\mathrm{x}}{2}\right)}
$$

The variable used in the computer program to express fuel composition is the mass ratio $y$ of hydrogen to carbon. In terms of this mass ratio, the atom ratio $x$ is

$$
x=\frac{12.010}{1.008} y=11.914683 y
$$

and the formula weights associated with the components of equation (B1) are $\mathrm{CH}_{\mathrm{x}}=12.010(1+\mathrm{y}), \mathrm{O}_{2}=32.000+95.317460 \mathrm{y}, \mathrm{CO}_{2}=44.010$, and $\mathrm{H}_{2} \mathrm{O}=107.327460 \mathrm{y}$.

If one mass unit of air, with an associated $\mathrm{m}$ mass units of water vapor, is reacted with $f$ mass units of fuel, the reactant and product masses $w$ per mass unit of air are as shown in table IV. The composition of the combustion gas used in the cycle analysis is defined by the product masses shown in table IV.

\section{Heat Capacity}

The heat capacity of the combustion gas is

$$
c_{p}=\frac{\sum\left(w c_{p}\right) \text { components }}{1+f+m}
$$

The heat capacity of each component is expressed in the form

$$
c_{p}=A+B T+C T^{2}+D T^{3}+E T^{4}
$$

The coefficients A, B, C, D, and E were obtained by a least-squares regression analysis of the tabulated data of reference 1 . These coefficients and the molecular weight of 
each component are given in table $\mathrm{V}$.

Equation (B3) for combustion gas heat capacity is evaluated by substituting for $w$ according to table IV and for $c_{p}$ according to equation.(B4). . Performing the summation yields

$$
\begin{aligned}
& c_{p}=\left(\frac{1}{1+f+m}\right)\left\{A_{a i r}+B_{a i r} T+C_{a i r} T^{2}+D_{a i r} T^{3}+E_{a i r} T^{4}\right. \\
& +\left(\frac{\mathrm{f}}{1+\dot{\mathrm{y}}}\right)\left[\mathrm{K}_{1}\left(\mathrm{~A}_{\mathrm{O}_{2}}+\mathrm{B}_{\mathrm{O}_{2}} \mathrm{~T}+\mathrm{C}_{\mathrm{O}_{2}} \mathrm{~T}^{2}+\mathrm{D}_{\mathrm{O}_{2}} \mathrm{~T}^{3}+\mathrm{E}_{\mathrm{O}_{2}} \mathrm{~T}^{4}\right)\right. \\
& +\mathrm{K}_{2}\left(\mathrm{~A}_{\mathrm{CO}_{2}}+\mathrm{B}_{\mathrm{CO}_{2}} \mathrm{~T}+\mathrm{C}_{\mathrm{CO}_{2}} \mathrm{~T}^{2}+\mathrm{D}_{\mathrm{CO}_{2}} \mathrm{~T}^{3}+\mathrm{E}_{\left.\left.\mathrm{CO}_{2} \mathrm{~T}^{4}\right)\right]}\right.
\end{aligned}
$$

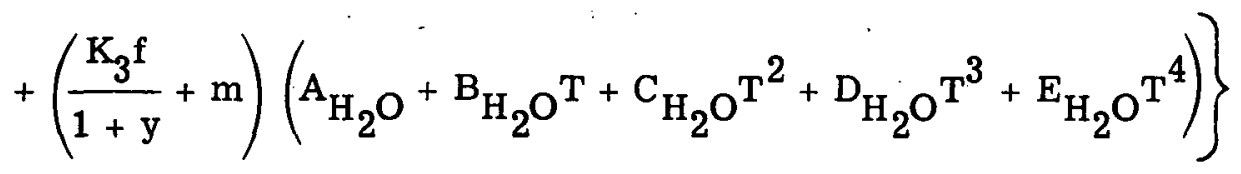

where

$$
\begin{gathered}
\mathrm{A}_{\text {air }}=1.00821 \mathrm{~J} /(\mathrm{kg})(\mathrm{K})\left(0.24062 \mathrm{Btu} /(\mathrm{lb})\left({ }^{\mathrm{O}} \mathrm{R}\right)\right) \\
\mathrm{B}_{\text {air }}=-1.33675 \times 10^{-1} \mathrm{~J} /(\mathrm{kg})\left(\mathrm{K}^{2}\right)\left(-0.017724 \times 10^{-3} \mathrm{Btu} /(\mathrm{lb})\left({ }^{\circ} \mathrm{R}^{2}\right)\right) \\
\mathrm{C}_{\text {air }}=5.16637 \times 10^{-4} \mathrm{~J} /(\mathrm{kg})\left(\mathrm{K}^{3}\right)\left(0.038056 \times 10^{-6} \mathrm{Btu} /(\mathrm{lb})\left({ }^{\mathrm{O}} \mathrm{R}^{3}\right)\right) \\
\mathrm{D}_{\text {air }}=-3.09412 \times 10^{-7} \mathrm{~J} /(\mathrm{kg})\left(\mathrm{K}^{4}\right)\left(-0.012662 \times 10^{-9} \mathrm{Btu} /(\mathrm{lb})\left({ }^{\circ} \mathrm{R}^{4}\right)\right) \\
\mathrm{E}_{\text {air }}=5.72336 \times 10^{-11} \mathrm{~J} /(\mathrm{kg})\left(\mathrm{K}^{5}\right)\left(0.0013012 \times 10^{-12} \mathrm{Btu} /(\mathrm{lb})\left({ }^{0} \mathrm{R}^{5}\right)\right) \\
\mathrm{K}_{1}=-2.6644(1+2.9787 \mathrm{y}) \\
\mathrm{K}_{2}=3.6644 \\
\mathrm{~K}_{3}=8.9365 \mathrm{y} .
\end{gathered}
$$

The $\mathrm{O}_{2}, \mathrm{CO}_{2}$, and $\mathrm{H}_{2} \mathrm{O}$ coefficients are as listed in table $\mathrm{V}$. The coefficients subscripted air were obtained by combining the component coefficients according to the air composition shown in table IV. 


\section{Enthalpy Change}

The change in gas enthalpy resulting from a change in gas temperature from $T_{1}$ to $\mathrm{T}_{2}$ is

$$
\Delta h=\int_{T_{1}}^{T_{2}} c_{p} d T
$$

Substituting equation (B5) into equation (B6) and integ rating yield

$$
\begin{aligned}
& \Delta h=\left(\frac{1}{1+f+m}\right)\left\langle A_{\text {air }}\left(T_{2}-T_{1}\right)+\frac{B_{\text {air }}}{2}\left(T_{2}^{2}-T_{1}^{2}\right)+\frac{C_{\text {air }}}{3}\left(T_{2}^{3}-T_{1}^{3}\right)\right. \\
& +\frac{\mathrm{D}_{\text {air }}}{4}\left(\mathrm{~T}_{2}^{4}-\mathrm{T}_{1}^{4}\right)+\frac{\mathrm{E}_{\text {air }}}{5}\left(\mathrm{~T}_{2}^{5}-\mathrm{T}_{1}^{5}\right)+\left(\frac{\mathrm{f}}{1+\mathrm{y}}\right)\left\{\mathrm { K } _ { 1 } \left[\mathrm{A}_{\mathrm{O}_{2}}\left(\mathrm{~T}_{2}-\mathrm{T}_{1}\right)+\frac{{ }^{\mathrm{B}} \mathrm{O}_{2}}{2}\left(\mathrm{~T}_{2}^{2}-\mathrm{T}_{1}^{2}\right)\right.\right. \\
& \left.+\frac{{ }^{\mathrm{C}_{2}}}{3}\left(\mathrm{~T}_{2}^{3}-\mathrm{T}_{1}^{3}\right)+\frac{{ }^{\mathrm{D}_{2}}}{4}\left(\mathrm{~T}_{2}^{4}-\mathrm{T}_{1}^{4}\right)+\frac{{ }^{\mathrm{E}} \mathrm{O}_{2}}{5}\left(\mathrm{~T}_{2}^{5}-\mathrm{T}_{1}^{5}\right)\right] \\
& +\mathrm{K}_{2}\left[{ }_{\mathrm{A} \mathrm{O}_{2}}\left(\mathrm{~T}_{2}-\mathrm{T}_{1}\right)+\frac{{ }^{\mathrm{B}} \mathrm{CO}_{2}}{2}\left(\mathrm{~T}_{2}^{2}-\mathrm{T}_{1}^{2}\right)+\frac{{ }^{\mathrm{C}} \mathrm{CO}_{2}}{3}\left(\mathrm{~T}_{2}^{3}-\mathrm{T}_{1}^{3}\right)+\frac{{ }^{\mathrm{D}}{ }_{\mathrm{CO}_{2}}}{4}\left(\mathrm{~T}_{2}^{4}-\mathrm{T}_{1}^{4}\right)\right. \\
& \left.+\frac{{ }^{\mathrm{E}} \mathrm{CO}_{2}}{5}\left(\mathrm{~T}_{2}^{5}-\mathrm{T}_{1}^{5}\right)\right]+\left(\frac{\mathrm{K}_{3} \mathrm{f}}{\mathrm{i}+\mathrm{y}}+\mathrm{m}\right)\left[\mathrm{A}_{\mathrm{H}_{2}} \mathrm{O}^{\left(\mathrm{T}_{2}\right.}-\mathrm{T}_{1}\right)+\frac{{ }_{\mathrm{H}_{2} \mathrm{O}}}{2}\left(\mathrm{~T}_{2}^{2}-\mathrm{T}_{1}^{2}\right) \\
& \left.\left.+\frac{\mathrm{C}_{\mathrm{H}_{2} \mathrm{O}}}{3}\left(\mathrm{~T}_{2}^{3}-\mathrm{T}_{1}^{3}\right)+\frac{\mathrm{D}_{\mathrm{H}_{2} \mathrm{O}}}{4}\left(\mathrm{~T}_{2}^{4}-\mathrm{T}_{1}^{4}\right)+\frac{\mathrm{E}_{\mathrm{H}_{2} \mathrm{O}}}{5}\left(\mathrm{~T}_{2}^{5}-\mathrm{T}_{1}^{5}\right)\right]\right)
\end{aligned}
$$

For brevity in the cycle analysis procedure, equation (B7) will be expressed as

$$
\Delta \mathrm{h}=\mathrm{H}\left(\mathrm{T}_{1}, \mathrm{~T}_{2}, \mathrm{f}\right)
$$

In order to facilitate burner calculations, it is desired to extract the fuel-air ratio $f$ from the function $H$. To do this, equation (B8) is written 


$$
\Delta \mathrm{h}=\frac{1}{1+\mathrm{f}+\mathrm{m}}(1+\mathrm{m}) \mathrm{H}\left(\mathrm{T}_{1}, \mathrm{~T}_{2}, 0\right)+\mathrm{fI}\left(\mathrm{T}_{1}, \mathrm{~T}_{2}\right)
$$

Comparison of equation (B9) with equation (B7) shows that the function $I\left(T_{1}, T_{2}\right)$ is

$$
\begin{aligned}
& \mathrm{I}\left(\mathrm{T}_{1}, \mathrm{~T}_{2}\right)=\left(\frac{1}{1+\mathrm{y}}\right)\left\{\mathrm { K } _ { 1 } \left[\mathrm{A}_{\mathrm{O}_{2}}\left(\mathrm{~T}_{2}-\mathrm{T}_{1}\right)+\frac{{ }^{\mathrm{B}} \mathrm{O}_{2}}{2}\left(\mathrm{~T}_{2}^{2}-\mathrm{T}_{1}^{2}\right)+\frac{\mathrm{C}_{2}}{3}\left(\mathrm{~T}_{2}^{3}-\mathrm{T}_{1}^{3}\right)\right.\right. \\
& \left.+\frac{\mathrm{D}_{2}}{4}\left(\mathrm{~T}_{2}^{4}-\mathrm{T}_{1}^{4}\right)+\frac{{ }^{\mathrm{E}} \mathrm{O}_{2}}{5}\left(\mathrm{~T}_{2}^{5}-\mathrm{T}_{1}^{5}\right)\right]+\mathrm{K}_{2}\left[\mathrm{~A}_{\mathrm{CO}_{2}}\left(\mathrm{~T}_{2}-\mathrm{T}_{1}\right)+\frac{{ }^{\mathrm{B}} \mathrm{CO}_{2}}{2}\left(\mathrm{~T}_{2}^{2}-\mathrm{T}_{1}^{2}\right)\right. \\
& \left.+\frac{{ }^{C_{C O}}}{3}\left(\mathrm{~T}_{2}^{3}-\mathrm{T}_{1}^{3}\right)+\frac{{ }^{\mathrm{D}} \mathrm{CO}_{2}}{4}\left(\mathrm{~T}_{2}^{4}-\mathrm{T}_{1}^{4}\right)+\frac{{ }^{\mathrm{E}} \mathrm{CO}_{2}}{5}\left(\mathrm{~T}_{2}^{5}-\mathrm{T}_{1}^{5}\right)\right] \\
& +\mathrm{K}_{3}\left[\mathrm{~A}_{\mathrm{H}_{2} \mathrm{O}}\left(\mathrm{T}_{2}-\mathrm{T}_{1}\right)+\frac{\mathrm{B}_{\mathrm{H}_{2} \mathrm{O}}}{2}\left(\mathrm{~T}_{2}^{2}-\mathrm{T}_{1}^{2}\right)+\frac{\mathrm{C}_{\mathrm{H}_{2} \mathrm{O}}}{3}\left(\mathrm{~T}_{2}^{3}-\mathrm{T}_{1}^{3}\right)\right. \\
& \left.\left.+\frac{\mathrm{D}_{\mathrm{H}_{2} \mathrm{O}}}{4}\left(\mathrm{~T}_{2}^{4}-\mathrm{T}_{1}^{4}\right)+\frac{{ }_{\mathrm{H}_{2} \mathrm{O}}}{5}\left(\mathrm{~T}_{2}^{5}-\mathrm{T}_{1}^{5}\right)\right]\right\}
\end{aligned}
$$

\section{Constant-Pressure Entropy Change}

The change in gas entropy resulting from a change in gas temperature from $T_{1}$ to $\mathrm{T}_{2}$ at constant pressure is

$$
\Delta \varphi=\int_{\mathrm{T}_{1}}^{\mathrm{T}_{2} \frac{\mathrm{c}}{\mathrm{T}}} \frac{\mathrm{dT}}{\mathrm{T}}
$$

This function is used in the evaluation of ideal (isentropic) and polytropic processes in turbomachines. Substituting equation (B5) into equation (B11) and integrating yield 


$$
\begin{aligned}
& \Delta \varphi=\left(\frac{1}{1+\mathrm{f}+\mathrm{m}}\right)\left(\mathrm{A}_{\text {air }} \ln \frac{\mathrm{T}_{2}}{\mathrm{~T}_{1}}+\mathrm{B}_{\text {air }}\left(\mathrm{T}_{2}-\mathrm{T}_{1}\right)+\frac{\mathrm{C}_{\text {air }}}{2}\left(\mathrm{~T}_{2}^{2}-\mathrm{T}_{1}^{2}\right)+\frac{\mathrm{D}_{\text {air }}}{3}\left(\mathrm{~T}_{2}^{3}-\mathrm{T}_{1}^{3}\right)\right. \\
& +\frac{\mathrm{E}_{\text {air }}}{4}\left(\mathrm{~T}_{2}^{4}-\mathrm{T}_{1}^{4}\right)+\left(\frac{\mathrm{f}}{1+\mathrm{y}}\right)\left\{\mathrm { K } _ { 1 } \left[\mathrm{A}_{\mathrm{O}_{2}} \ln \frac{\mathrm{T}_{2}}{\mathrm{~T}_{1}}+\mathrm{B}_{\mathrm{O}_{2}}\left(\mathrm{~T}_{2}-\mathrm{T}_{1}\right)+\frac{\mathrm{C}_{\mathrm{O}_{2}}}{2}\left(\mathrm{~T}_{2}^{2}-\mathrm{T}_{1}^{2}\right)\right.\right. \\
& \left.+\frac{{ }^{\mathrm{O}_{2}}}{3}\left(\mathrm{~T}_{2}^{3}-\mathrm{T}_{1}^{3}\right)+\frac{{ }^{\mathrm{E}} \mathrm{O}_{2}}{4}\left(\mathrm{~T}_{2}^{4}-\mathrm{T}_{1}^{4}\right)\right]+\mathrm{K}_{2}\left[\mathrm{~A}_{\mathrm{CO}_{2}} \ln \frac{\mathrm{T}_{2}}{\mathrm{~T}_{1}}+\mathrm{B}_{\mathrm{CO}_{2}}\left(\mathrm{~T}_{2}-\mathrm{T}_{1}\right)\right. \\
& \left.\left.+\frac{{ }^{C} O_{2}}{2}\left(\mathrm{~T}_{2}^{2}-\mathrm{T}_{1}^{2}\right)+\frac{{ }^{\mathrm{D}_{2}}}{3}\left(\mathrm{~T}_{2}^{3}-\mathrm{T}_{1}^{3}\right)+\frac{{ }^{\mathrm{E}_{\mathrm{CO}}}}{4}\left(\mathrm{~T}_{2}^{4}-\mathrm{T}_{1}^{4}\right)\right]\right\} \\
& +\left(\frac{\mathrm{K}_{3} \mathrm{f}}{1+\mathrm{y}}+\mathrm{m}\right)\left[\mathrm{A}_{\mathrm{H}_{2} \mathrm{O}} \ln \frac{\mathrm{T}_{2}}{\mathrm{~T}_{1}}+\mathrm{B}_{\mathrm{H}_{2} \mathrm{O}}\left(\mathrm{T}_{2}-\mathrm{T}_{1}\right)+\frac{\mathrm{C}_{\mathrm{H}_{2} \mathrm{O}}}{2}\left(\mathrm{~T}_{2}^{2}-\mathrm{T}_{1}^{2}\right)\right. \\
& \left.\left.+\frac{\mathrm{D}_{\mathrm{H}_{2} \mathrm{O}}}{3}\left(\mathrm{~T}_{2}^{3}-\mathrm{T}_{1}^{3}\right)+\frac{\mathrm{E}_{\mathrm{H}_{2} \mathrm{O}}}{4}\left(\mathrm{~T}_{2}^{4}-\mathrm{T}_{1}^{4}\right)\right]\right\rangle
\end{aligned}
$$

For brevity in the cycle analysis procedure, equation (B12) will be expressed as

$$
\Delta \varphi=\Phi\left(\mathrm{T}_{1}, \mathrm{~T}_{2}, \mathrm{f}\right)
$$

\section{Molecular Weight}

The molecular weight of the gas is equal to the weight of the gas divided by the total number of moles (sum of the moles of the components). Therefore, molecular weight can be expressed as

$$
M=\frac{1+f+m}{\sum\left(\frac{w}{M}\right)_{\text {components }}}
$$


With $\mathrm{w}$ obtained from table IV and $\mathrm{M}$ from table $\mathrm{V}$, equation (B14) expands to

$$
M=\frac{1+f+m}{0.034522+0.24802 y\left(\frac{f}{1+y}\right)+\frac{m}{18.016}}
$$




\section{APPENDIX C}

\section{FUEL PROPERTIES AND COMPRESSION}

Thermodynamic Properties

The heat capacity of the $\mathrm{CH}_{\mathrm{X}}$ fuel is expressed as

$$
c_{p, f}=A_{f}+B_{f} T+C_{f} T^{2}
$$

The coefficients $A_{f}, B_{f}$, and $C_{f}$ depend on the particular fuel being used and must be provided as program input.

The change in fuel enthalpy with temperature change, in accordance with equation (B6), is

$$
\Delta \mathrm{h}_{\mathrm{f}}=\mathrm{A}_{\mathrm{f}}\left(\mathrm{T}_{2}-\mathrm{T}_{1}\right)+\frac{\mathrm{B}_{\mathrm{f}}}{2}\left(\mathrm{~T}_{2}^{2}-\mathrm{T}_{1}^{2}\right)+\frac{\mathrm{C}_{\mathrm{f}}}{3}\left(\mathrm{~T}_{2}^{3}-\mathrm{T}_{1}^{3}\right)
$$

In accordance with equation (B11), the change in fuel entropy resulting from a temperature change at constant pressure is

$$
\Delta \varphi_{\mathrm{f}}=\mathrm{A}_{\mathrm{f}} \ln \frac{\mathrm{T}_{2}}{\mathrm{~T}_{1}}+\mathrm{B}_{\mathrm{f}}\left(\mathrm{T}_{2}-\mathrm{T}_{1}\right)+\frac{\mathrm{C}_{\mathrm{f}}}{2}\left(\mathrm{~T}_{2}^{2}-\mathrm{T}_{1}^{2}\right)
$$

In a similar manner as was done for the combustion gas in appendix B, equations (C2) and (C3) will be expressed

$$
\Delta \mathrm{h}_{\mathrm{f}}=\mathrm{H}_{\mathrm{f}}\left(\mathrm{T}_{1}, \mathrm{~T}_{2}\right)
$$

and

$$
\Delta \varphi_{\mathrm{f}}=\Phi_{\mathrm{f}}\left(\mathrm{T}_{1}, \mathrm{~T}_{2}\right)
$$

\section{Fuel Compression}

In some cases it may be necessary to compress the fuel in order to get it into the burner. For such a case, it may be desirable to charge the cycle output for the fuelcompression power. The program provides for the computation of fuel compression work with or without intercooling. Although it is recognized that a gaseous fuel may 
deviate significantly from ideal-gas behavior, an ideal-gas analysis is us ed because the fuel-compression power is small as compared with the cycle output power.

The fuel inlet temperature $T_{f, \text { in }}^{\prime}$, fuel inlet pressure $p_{f}^{\prime}$, in, fuel compressor polytropic efficiency $\eta_{C, f, p}$, and number of compressors $n_{C, f}$ with intervening intercoolers are specified by the program input. It is assumed that the fuel must be compressed to a pressure defined by the cycle pressure ratio $r_{c y}$

$$
\mathrm{p}_{\mathrm{f}, \mathrm{C}, \mathrm{ex}}^{\prime}=\mathrm{p}_{0} \mathrm{r}_{\mathrm{cy}}
$$

Each fuel compressor is assumed to have the same pressure ratio

$$
r_{C, f}=\left(\frac{p_{f, c, e x}^{\prime}}{p_{f, i n}^{\prime}}\right)^{1 / n_{C, f}}
$$

and each intercooler is assumed to cool the fuel back to the fuel inlet temperature $\mathrm{T}_{\mathrm{f} \text {, in }}^{\prime}$. The fuel-compressor exit temperature $\mathrm{T}_{\mathrm{f}, \mathrm{C}, \mathrm{ex}}^{\prime}$ is then obtained from

$$
\Phi_{f}\left(T_{f, i n}^{\prime}, T_{f, C, e x}^{\prime}\right)=\frac{1}{\eta_{C, f, p}} \frac{R_{f}}{J} \ln r_{C, f}
$$

and the fuel-compression specific work is

$$
\left.\Delta h_{f, C}^{\prime}=n_{C, f^{H}} H_{f, i n}, T_{f, C, e x}^{\prime}\right)
$$




\section{REFERENCE}

1. McBride, Bonnie J.; Heimel, Sheldon; Ehlers, Janet G.; and Gordon, Sanford: Thermodynamic Properties to $6000^{\circ} \mathrm{K}$ for 210 Substances Involving the First 18 Elements. NASA SP-3001, 1963. 
$\therefore$ 家 $\infty$ न 11 न 0 [ $\infty$ N $\infty \begin{array}{ll} & -1 \\ 0 & 0\end{array}$ iा U $U$ a

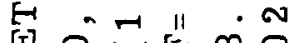
- 2 Z出 $\infty$. H. D $\therefore$ i $90 \sum^{N}$ A $N$.

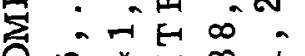
in $*$ in $\infty \omega$

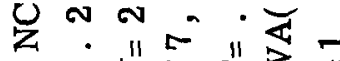

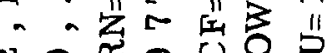

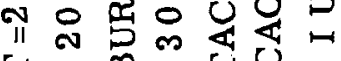
स. . H स ת a a Z $=N$ : क मे 自 $\infty$ Z

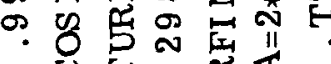
II U स II

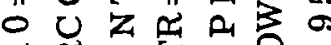

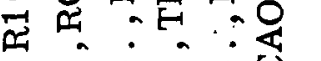
- $\infty \dot{0} \infty \dot{\infty}<\ll$ - $\begin{array}{llll}0 & 0 & \infty & B\end{array}$ - * II O II 0

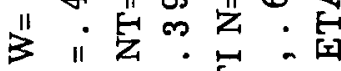

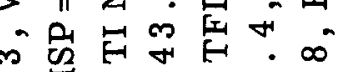
$\rightarrow$ 在 0 11

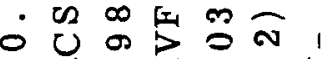

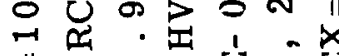

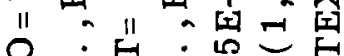

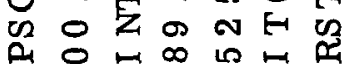

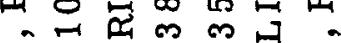

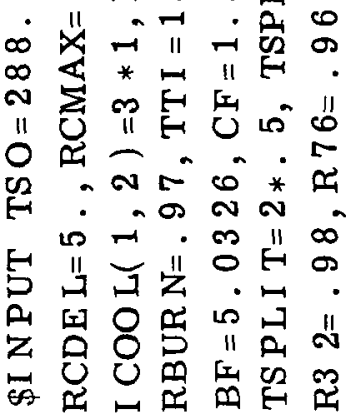



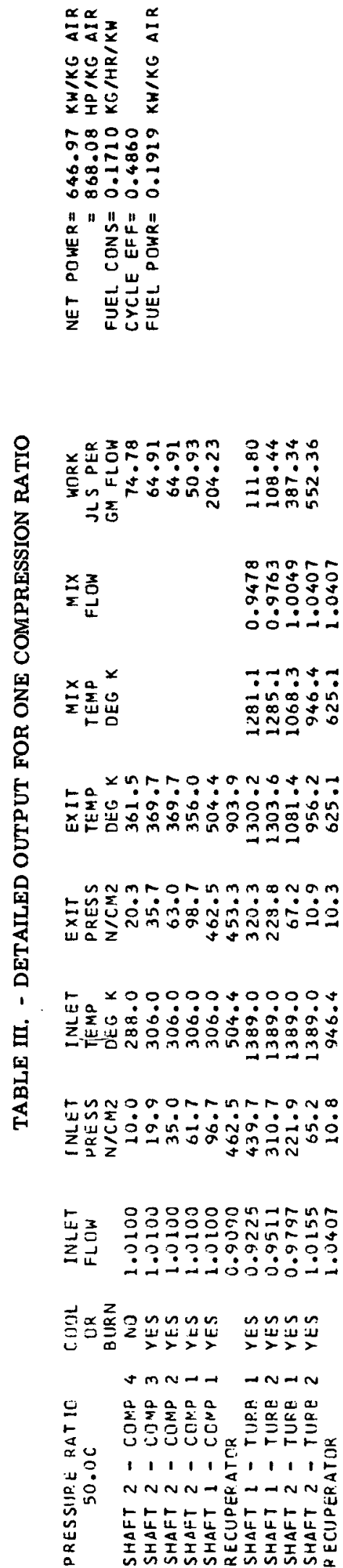
TABLE II. - OUTPUT FOR ILLUSTRATIVE EXAMPLE

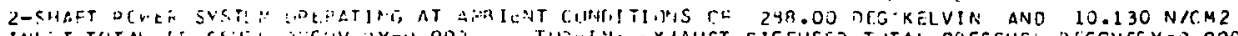

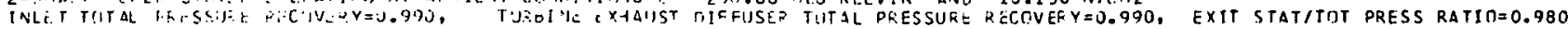

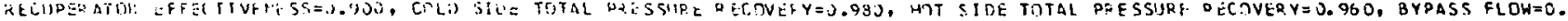

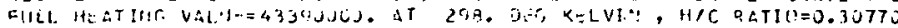

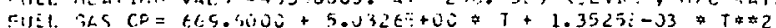

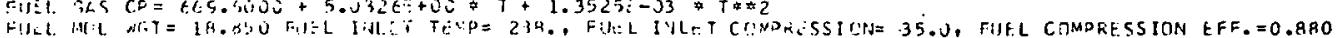

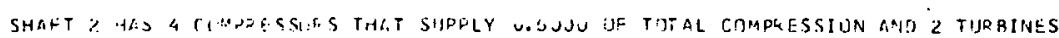

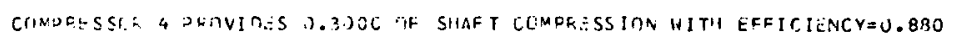

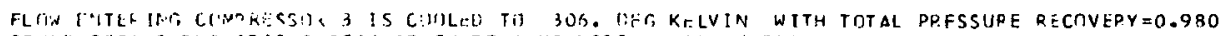

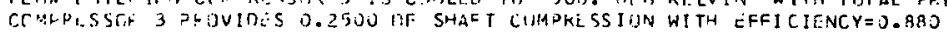

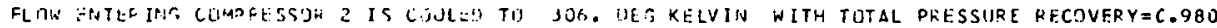

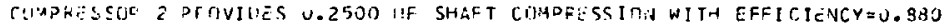

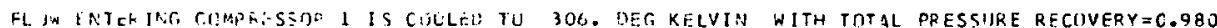

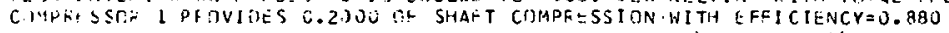

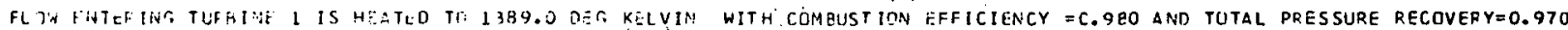

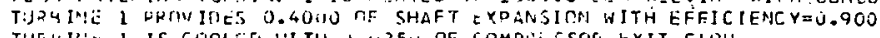

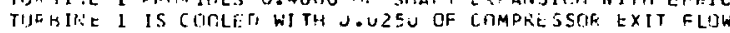

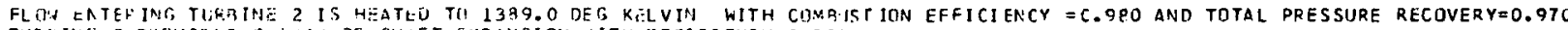

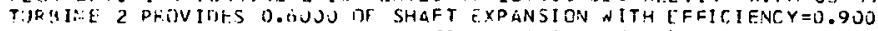

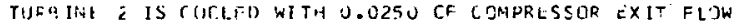

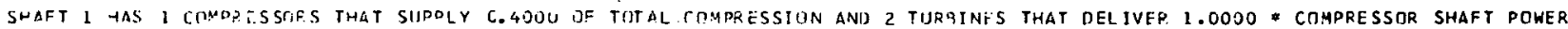

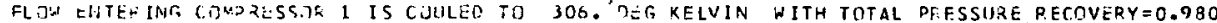

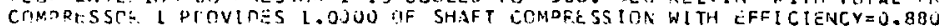

FLIJW INIEHING TUFFIHE I IS HEATED TU 1389.0 "DEG KELVIN WITH CJMRIIST IOH EFFICIENCY =C. 980 AND TOTAL PRESSURE RECOVERY=0.970

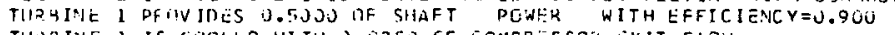

TIJRBINF I IS TOOL:D WITH 0.0250 CF COMPRESSOR EXIT FLOW

FL DU ENT

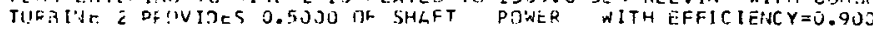

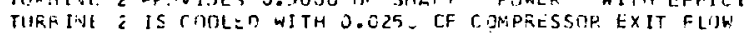

OUTPUT PIJWEF EOLLLS 0.9500 TF SHAFT POWEK

TUR BCMACHINEDY EFFICIENCIES ARE PJLYTRIPIZ

\begin{tabular}{|c|c|c|c|c|c|}
\hline \multirow{3}{*}{$\begin{array}{l}\text { Po: } 5 S . \\
\text { Rsin }\end{array}$} & $A=T$ & Ni:T & FUむl & CYCLLE & FIJEL \\
\hline & $=r+t r$ & DE VE= & cinsune. & EFF & DISWER \\
\hline & Kis & HP & $K G / H A / K: v$ & & $\mathrm{KW}$ \\
\hline $\begin{array}{r}5.00 \\
10.00\end{array}$ & $\begin{array}{l}255.96 \\
385.26\end{array}$ & $\begin{array}{l}343.3 \mathrm{~J} \\
520.95\end{array}$ & $\begin{array}{l}3.2244 \\
0.1898\end{array}$ & $\begin{array}{l}0.377 \mathrm{~J} \\
0.4379\end{array}$ & $\begin{array}{l}0 . \\
0 .\end{array}$ \\
\hline 15.03 & 490.74 & 616.97 & 0.1314 & 0.4582 & 0. \\
\hline $20.0 !$ & 〔૮?.87 & 691.44 & 0.1774 & 0.4684 & 0. \\
\hline 25.00 & 543.73 & 729.56 & L. 1751 & 0.4745 & 0. \\
\hline 30.03 & $572.1 \mathrm{~J}$ & 767.52 & 0.1730 & 0.4785 & 0. \\
\hline 35.00 & 555.43 & 79.9 .53 & 0.1726 & 0.4814 & 0. \\
\hline 40.00 & $(1 ; .1 \%$ & 825.41 & 0.1719 & 0.4834 & 0.0031 \\
\hline 45.00 & $(=2.20)$ & 348.27 & 0.1714 & 0.4949 & 0.0060 \\
\hline 50.03 & 645.97 & คด $9.0 \mathrm{O}$ & 0.1710 & 0.4853 & 0.1919 \\
\hline 55.00 & 659.85 & 9.95 .17 & 0.1707 & 0.4857 & 0.6053 \\
\hline 60.30 & $81 .+40$ & 300.37 & 0.170 .5 & 0.4873 & 0.7981 \\
\hline $65.3 j$ & EEL.3S & 914.199 & $0.170 \%$ & 0.4877 & 1.3811 \\
\hline $73.0 \mathrm{~J}$ & $(91.37$ & 927.65 & 0.1703 & 0.4383 & 1.7471 \\
\hline $75.0 \mathrm{~J}$ & $7 c i .10$ & 739.39 & t. 1702 & $0.488 \bar{x}$ & 2.1000 \\
\hline $80.0 \mathrm{~J}$ & 73.15 & 950.19 & 0.2702 & 0.4853 & 2.4430 \\
\hline 85.00 & 715.02 & $96(.2)$, & 0.1701 & $0.488 \%$ & 2.7726 \\
\hline co.ju & 722.95 & 955.52 & 5.1701 & 0.4984 & 3.0955 \\
\hline 55.30 & $72^{\circ} .20$ & 979.23 & 0.1701 & 0.4884 & 3.4054 \\
\hline 100.00 & 735.14 & 986.39 & 0.1702 & 0.4884 & 3.7105 \\
\hline
\end{tabular}

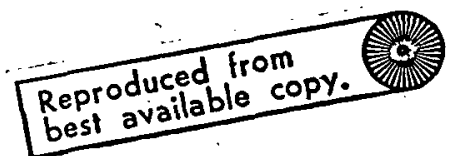


TABLE IV. - COMBUSTION REACTION STOICHIOMETRY

\begin{tabular}{|c|c|c|c|}
\hline Component & $\begin{array}{c}\text { Reactant } \\
\text { mass per } \\
\text { unit mass } \\
\text { of air }\end{array}$ & $\begin{array}{l}\text { Mass formed }(+) \text { or consumed }(-) \\
\text { by reaction per unit mass of air }\end{array}$ & Product mass per unit mass of air \\
\hline $\mathrm{N}_{2}$ & 0.7552 & 0 & 0.7552 \\
\hline $\mathrm{O}_{2}$ & .2314 & $-\frac{32.000+95.317460 \mathrm{y}}{\mathrm{f}}$ & $0.2314-\frac{2.664446+7.936508 \mathrm{y}}{1+f} \mathrm{f}$ \\
\hline A & .0129 & 0 & 0.0129 \\
\hline $\mathrm{CO}_{2}$ & .0005 & $+\frac{44.010}{12.010(1+y)} f$ & $0.0005+\frac{3.664446 \mathrm{y}}{1+\mathrm{y}} \mathrm{f}$ \\
\hline $\mathrm{H}_{2} \mathrm{O}$ & $\mathrm{m}$ & $+\frac{107.327460 \mathrm{y}}{12.010(1+\mathrm{y})} \mathrm{f}$ & $\mathrm{m}+\frac{8.936508 \mathrm{y}}{1+\mathrm{y}} \mathrm{f}$ \\
\hline $\mathrm{CH}_{\mathrm{x}}$ & f & $\quad \quad^{-\mathbf{f}}$ & 0 \\
\hline Total & $1+m+f$ & 0 & $1+m+f$ \\
\hline
\end{tabular}

TABLE V. - COEFFICIENTS AND MOLECULAR WEIGHTS OF COMPONENTS

\begin{tabular}{|c|c|c|c|c|c|c|}
\hline \multirow{2}{*}{$\begin{array}{c}\text { Compo- } \\
\text { nents }\end{array}$} & \multicolumn{5}{|c|}{ Coefficients in equation (B4), SI units (U.S. customary units) } & \multirow{2}{*}{$\begin{array}{c}\text { Molecular } \\
\text { weight } \\
\text { M }\end{array}$} \\
\hline & A & B & $\mathrm{C}$ & $\mathbf{D}^{\circ}$ & E & \\
\hline $\mathrm{N}_{2}$ & $\begin{array}{l}1064.69 \\
(0.25410)\end{array}$ & $\begin{array}{l}-246.550 \times 10^{-3} \\
\left(-0.032690 \times 10^{-3}\right)\end{array}$ & $\begin{array}{c}647.357 \times 10^{-6} \\
\left(0.047685 \times 10^{-6}\right)\end{array}$ & $\begin{array}{l}-365.884 \times 10^{-9} \\
\left(-0.014973 \times 10^{-9}\right)\end{array}$ & $\begin{array}{l}65.4721 \times 10^{-12} \\
\left(0.0014885 \times 10^{-12}\right)\end{array}$ & 28. 016 \\
\hline $\mathrm{O}_{2}$ & $\begin{array}{c}852.001 \\
(0.20334)\end{array}$ & $\begin{array}{l}223.848 \times 10^{-3} \\
\left(0.029680 \times 10^{-3}\right)\end{array}$ & $\begin{array}{c}122.142 \times 10^{-6} \\
\left(0.0089971 \times 10^{-6}\right)\end{array}$ & $\begin{array}{l}-143.788 \times 10^{-9} \\
\left(-0.0058842 \times 10^{-9}\right)\end{array}$ & $\begin{array}{l}33.7649 \times 10^{-12} \\
\left(0.00076764 \times 10^{-12}\right)\end{array}$ & 32.000 \\
\hline $\mathrm{CO}_{2}$ & $\begin{array}{r}464.968 \\
(0.11097)\end{array}$ & $\begin{array}{l}1592.13 \times 10^{-3} \\
\left(0.21110 \times 10^{-3}\right)\end{array}$ & $\begin{array}{l}-1196.56 \times 10^{-6} \\
\left(-0.088140 \times 10^{-6}\right)\end{array}$ & $\begin{array}{l}439.926 \times 10^{-9} \\
\left(0.018003 \times 10^{-9}\right)\end{array}$ & $\begin{array}{l}-62.9737 \times 10^{-12} \\
\left(-0.0014317 \times 10^{-12}\right)\end{array}$ & 44.010 \\
\hline $\mathrm{H}_{2} \mathrm{O}$ & $\begin{array}{l}1854.76 \\
(0.44266)\end{array}$ & $\begin{array}{l}-250.057 \times 10^{-3} \\
\left(-0.033155 \times 10^{-3}\right)\end{array}$ & $\begin{array}{l}1191.42 \times 10^{-6} \\
\left(0.087761 \times 10^{-6}\right)\end{array}$ & $\begin{array}{l}-599.959 \times 10^{-9} \\
\left(-0.024552 \times 10^{-9}\right)\end{array}$ & $\begin{array}{l}95.5976 \times 10^{-12} \\
\left(0.0021734 \times 10^{-12}\right)\end{array}$ & 18.016 \\
\hline A & $\begin{array}{c}521.156 \\
(0.12438)\end{array}$ & $\begin{array}{c}0 \\
(0)\end{array}$ & $(0)^{0}$ & $\begin{array}{l}0 \\
(0)\end{array}$ & $\begin{array}{c}0 \\
(0)\end{array}$ & 39.944 \\
\hline
\end{tabular}




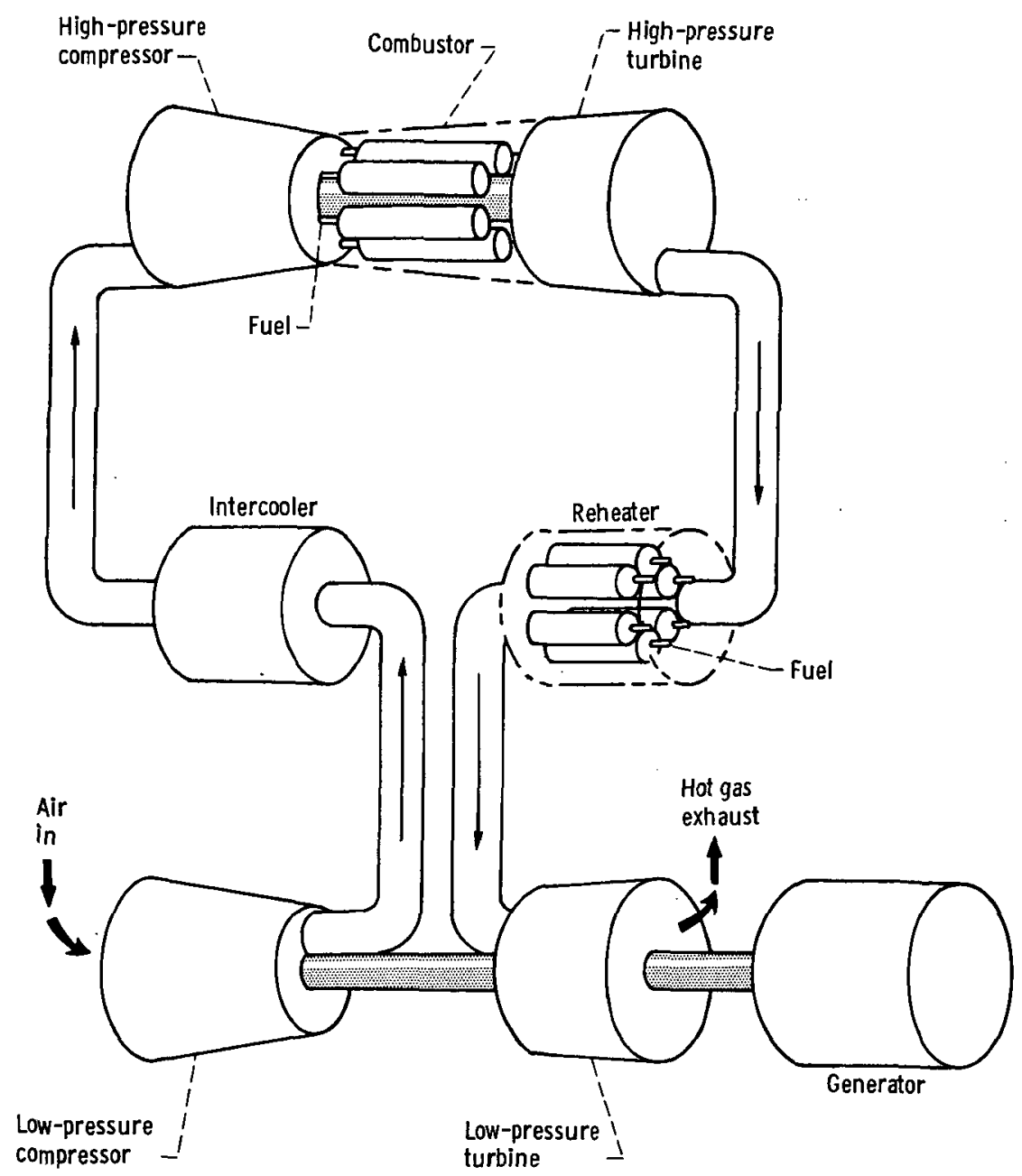

Figure 1. - Open-cycle system with intercooling and reheating.

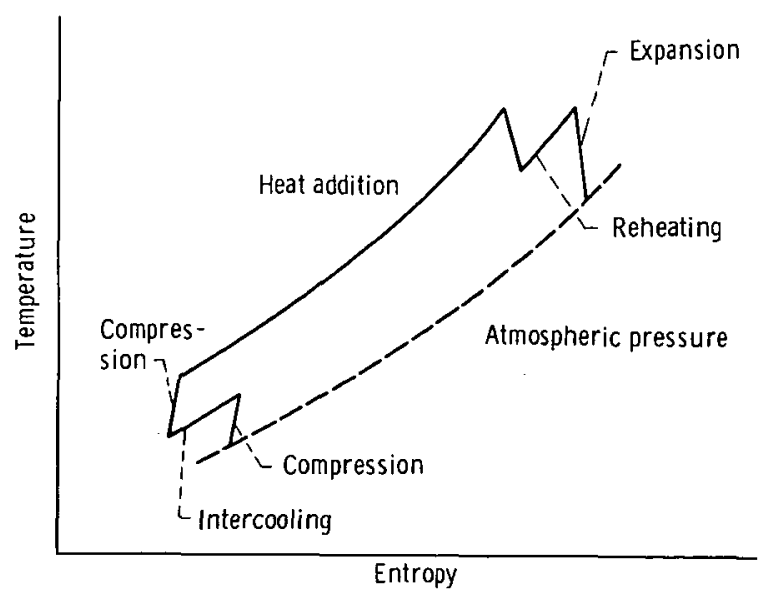

Figure 2. - Thermodynamic diagram for open-cycle system with intercooling and reheating. 

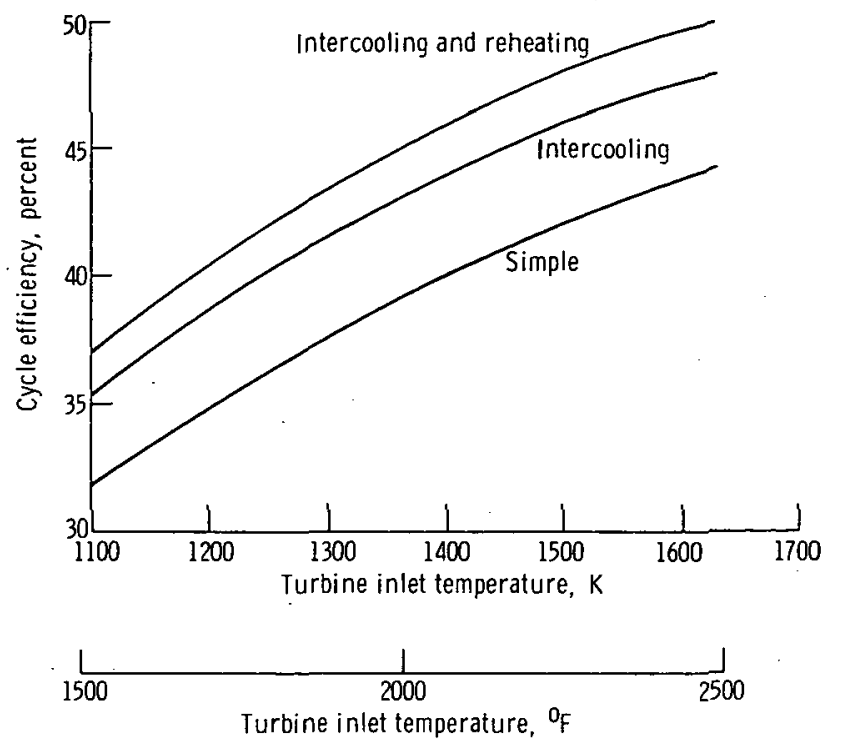

Figure 3. - Effect of intercooling and reheating on cycle efficiency at optimum pressure ratio. Compressor polytropic efficiency, 88 percent; turbine polytropic efficiency, 90 percent.

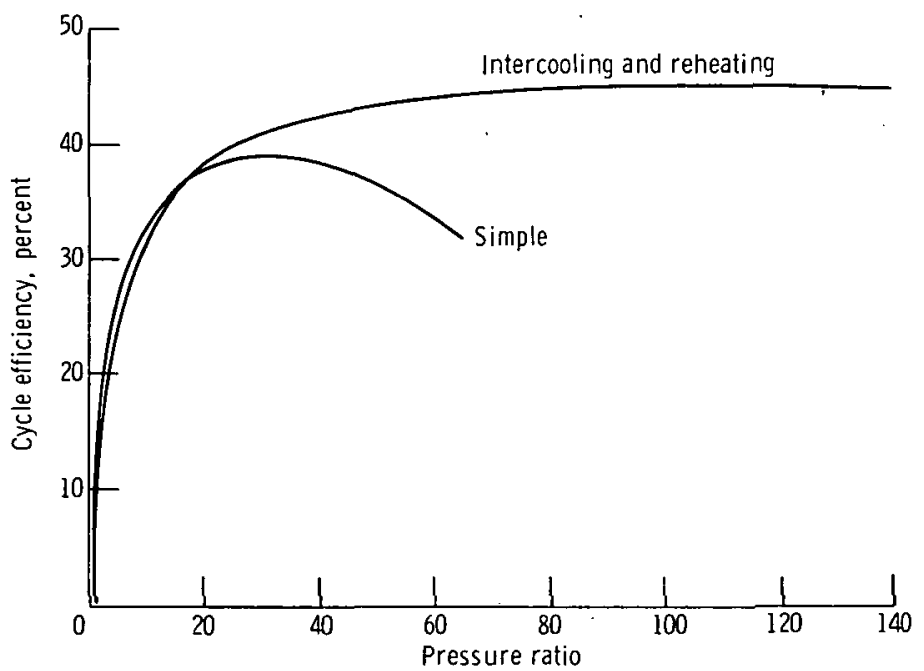

Figure 4. - Effect of intercooling and reheating on pressure ratio selection. Turbine inlet temperature, $1367 \mathrm{~K}\left(2000^{\circ} \mathrm{F}\right)$. 


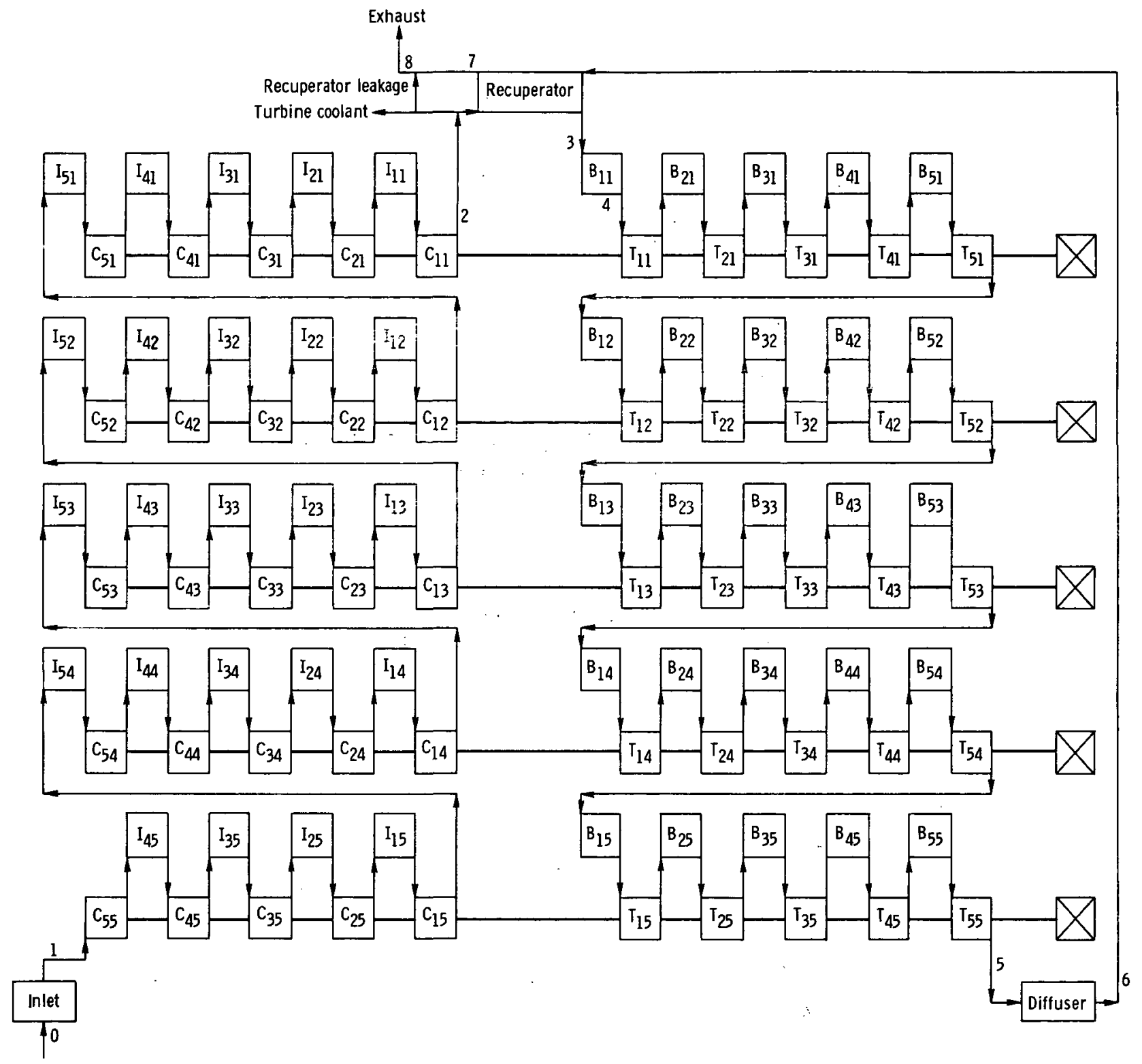

(a) Maximum number of components.

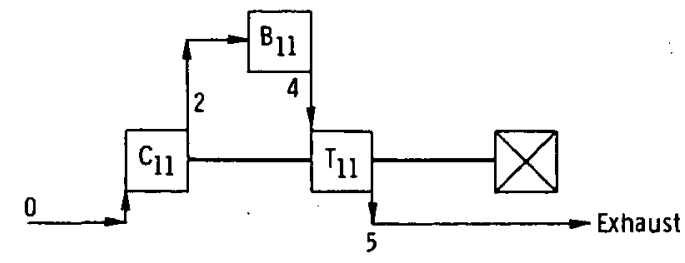

Intercooler

Compressor

Burner

Turbine

(b) Minimum number of components.

Figure 5. - Open-cycle power system schematic. 


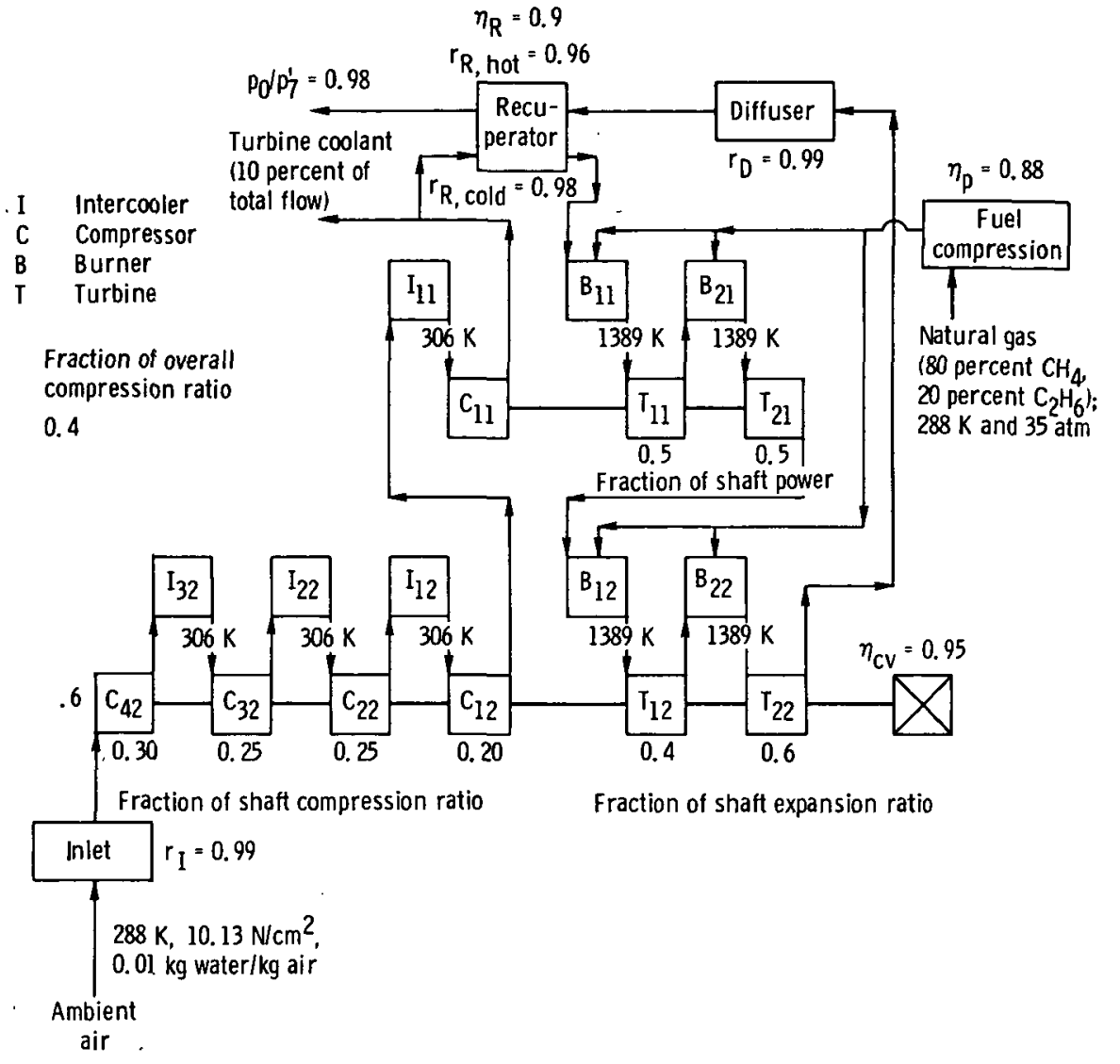

Figure 6. - Illustrative power system for example input and output. The following values are the same for all components of the same type: $\eta_{C, p}=0.88, r_{\text {INT }}=0.98, \eta_{B}=0.98, r_{B}=0.97$, $n_{T, p}=0.90$, and $w_{T,} c^{/ w_{1}}=0.025$. 
"The aeronautical and space activities of the United States shall be conducted so as to contribute ... to the expansion of human knowledge of phenomena in the atmosphere and space. The Administration shall provide for the widest practicable and appropriate dissemination of information concerning its activities and the results thereof."

\section{NASA SCIENTIFIC AND TECHNICAL PUBLICATIONS}

TECHNICAL REPORTS: Scientific and technical information considered important, complete, and a lasting contribution to existing knowledge.

TECHNICAL NOTES: Information less broad in scope but nevertheless of importance as a contribution to existing knowledge.

TECHNICAL MEMORANDUMS:

Information receiving limited distribution because of preliminary data, security classification, or other reasons. Also includes conference proceedings with either limited or unlimited distribution.

CONTRACTOR REPORTS: Scientific and technical information generated under a NASA contract or grant and considered an important contribution to existing knowledge.
TECHNICAL TRANSLATIONS: Information published in a foreign language considered to merit NASA distribution in English.

SPECIAL PUBLICATIONS: Information derived from or of value to NASA activities. Publications include final reports of major projects, monographs, data compilations, handbooks, sourcebooks, and special bibliographies.

\section{TECHNOLOGY UTILIZATION} PUBLICATIONS: Information on technology used by NASA that may be of particular interest in commercial and other non-aerospace applications. Publications include Tech Briefs, Technology Utilization Reports and Technology Surveys.

Details on the availability of these publications may be obtained from:

SCIENTIFIC AND TECHNICAL INFORMATION OFFICE 